Supporting Information For:

\title{
Synthesis and Reactivity of a U(IV) Dibenzyne Complex
}

\author{
Elizabeth A. Pedrick, Lani A. Seaman, Joshua C. Scott, Leonel Griego, Guang Wu, \\ and Trevor W. Hayton*
}

Department of Chemistry and Biochemistry, University of California Santa Barbara, Santa Barbara, CA 93106

*To whom correspondence should be addressed. Email: hayton@chem.ucsb.edu 


\section{Table of Contents}

$\begin{array}{ll}\text { NMR Spectra } & \text { S3 }\end{array}$

$\begin{array}{ll}\text { IR Spectra } & \text { S18 }\end{array}$

$\begin{array}{ll}\text { UV-Vis-NIR Spectra } & \text { S22 }\end{array}$

$\begin{array}{lr}\text { References } & \text { S24 }\end{array}$ 


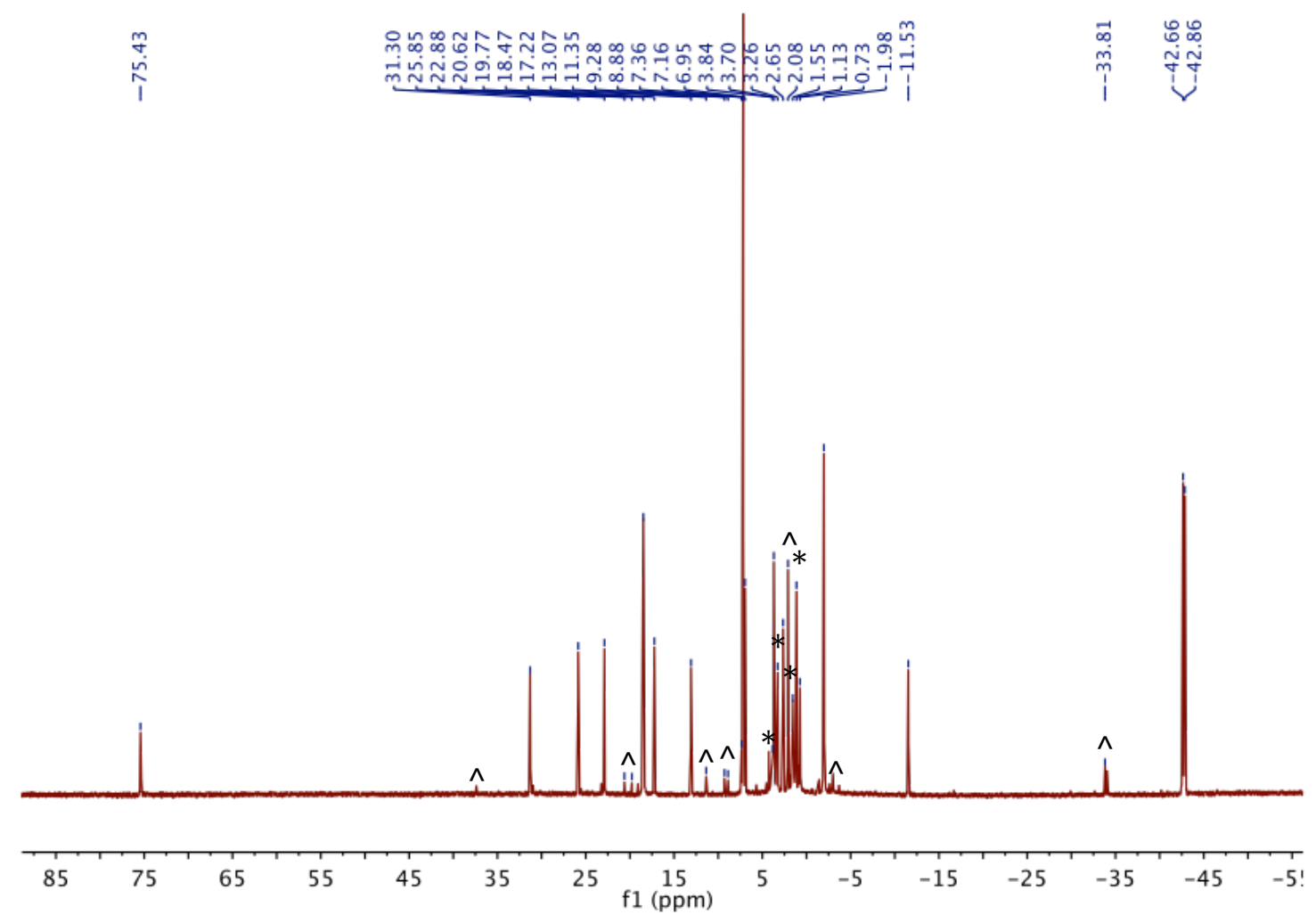

Figure S1. ${ }^{1} \mathrm{H}$ NMR spectrum of complex 1 in $\mathrm{C}_{6} \mathrm{D}_{6} \cdot{ }^{\wedge}$ indicates the presence of a minor unidentified impurity, and asterisks indicate the presence of $\mathrm{Et}_{2} \mathrm{O}$ and THF. 


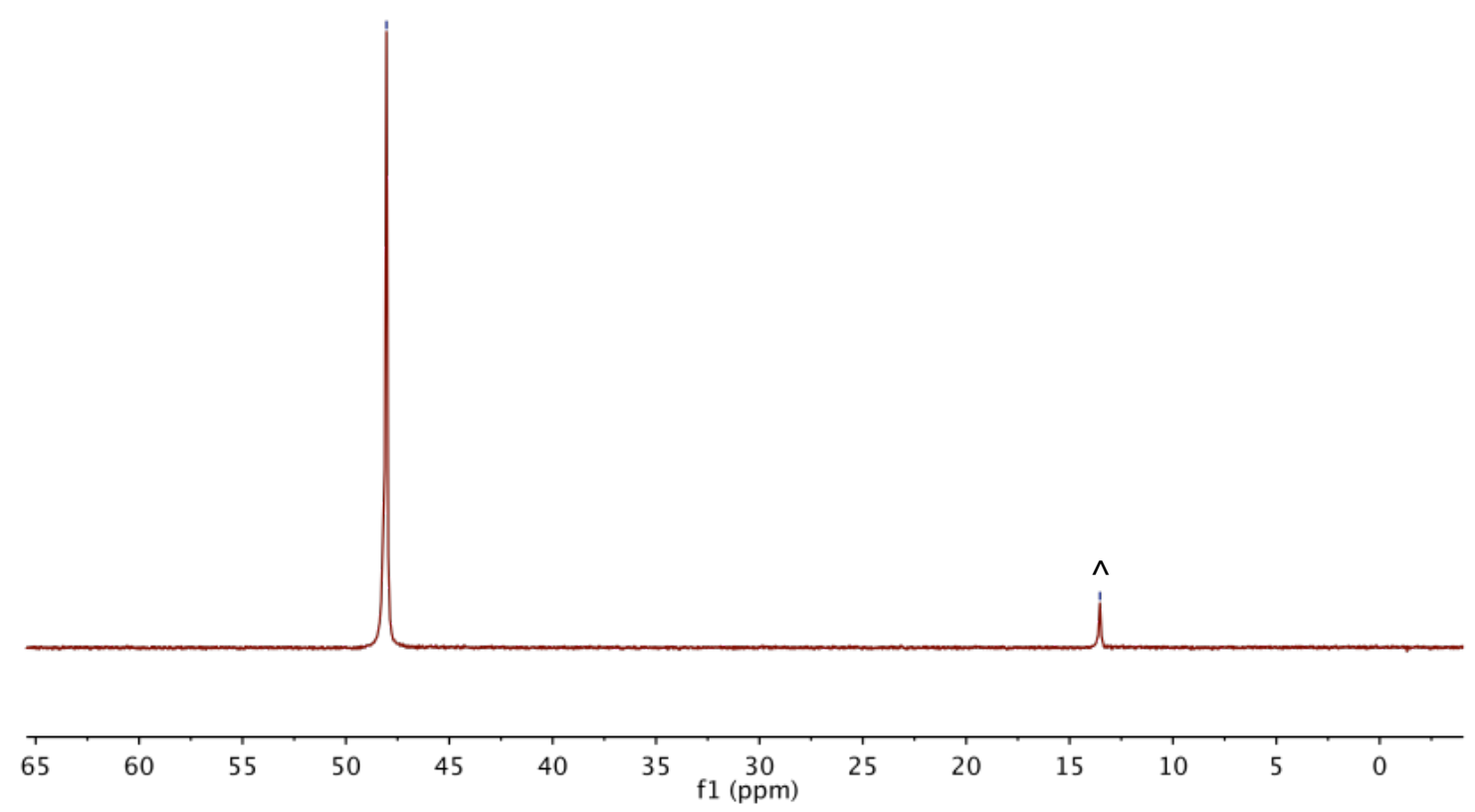

Figure S2. ${ }^{7} \mathrm{Li}\left\{{ }^{1} \mathrm{H}\right\}$ NMR spectrum of complex 1 in $\mathrm{C}_{6} \mathrm{D}_{6} \cdot{ }^{\wedge}$ indicates the presence of a minor unidentified impurity. 


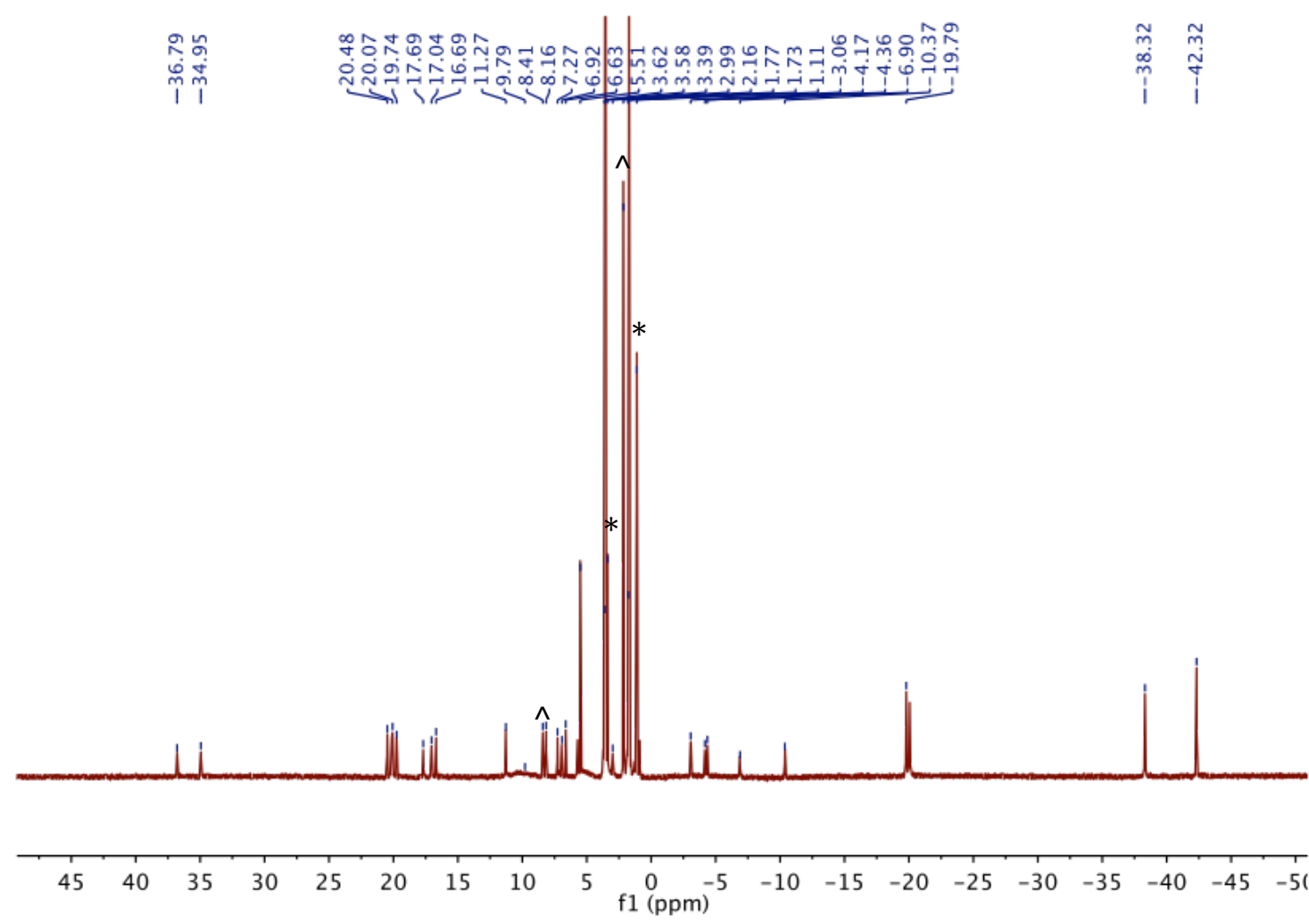

Figure S3. ${ }^{1} \mathrm{H}$ NMR spectrum of complex 1 in THF- $d_{8}$. Asterisks indicate the presence of $\mathrm{Et}_{2} \mathrm{O}$ and ${ }^{\wedge}$ indicates the resonances assignable to free dimethylbenzylamine. 


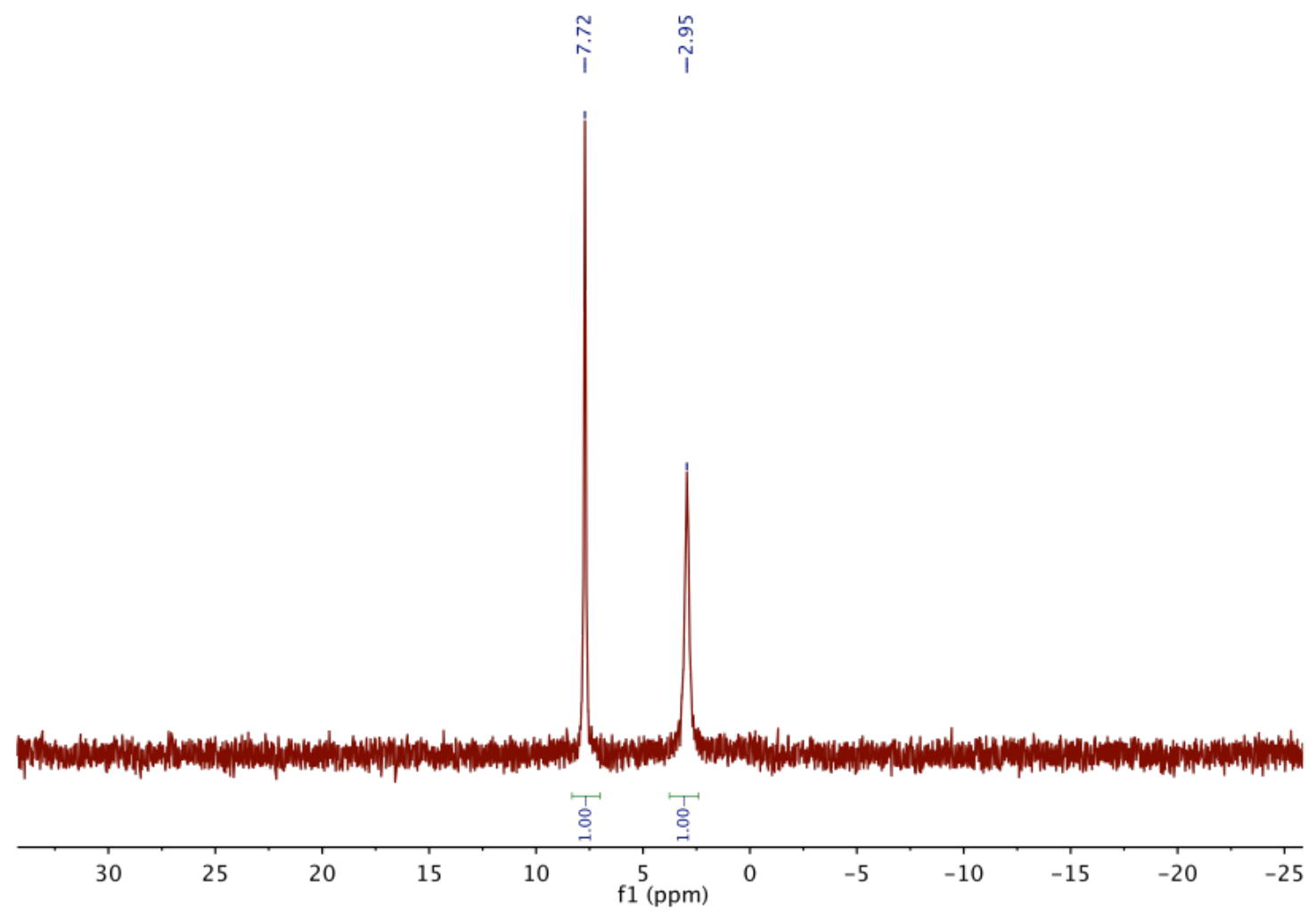

Figure S4. ${ }^{7} \mathrm{Li}\left\{{ }^{1} \mathrm{H}\right\}$ NMR spectrum of complex 2 in THF- $d_{8}$. 


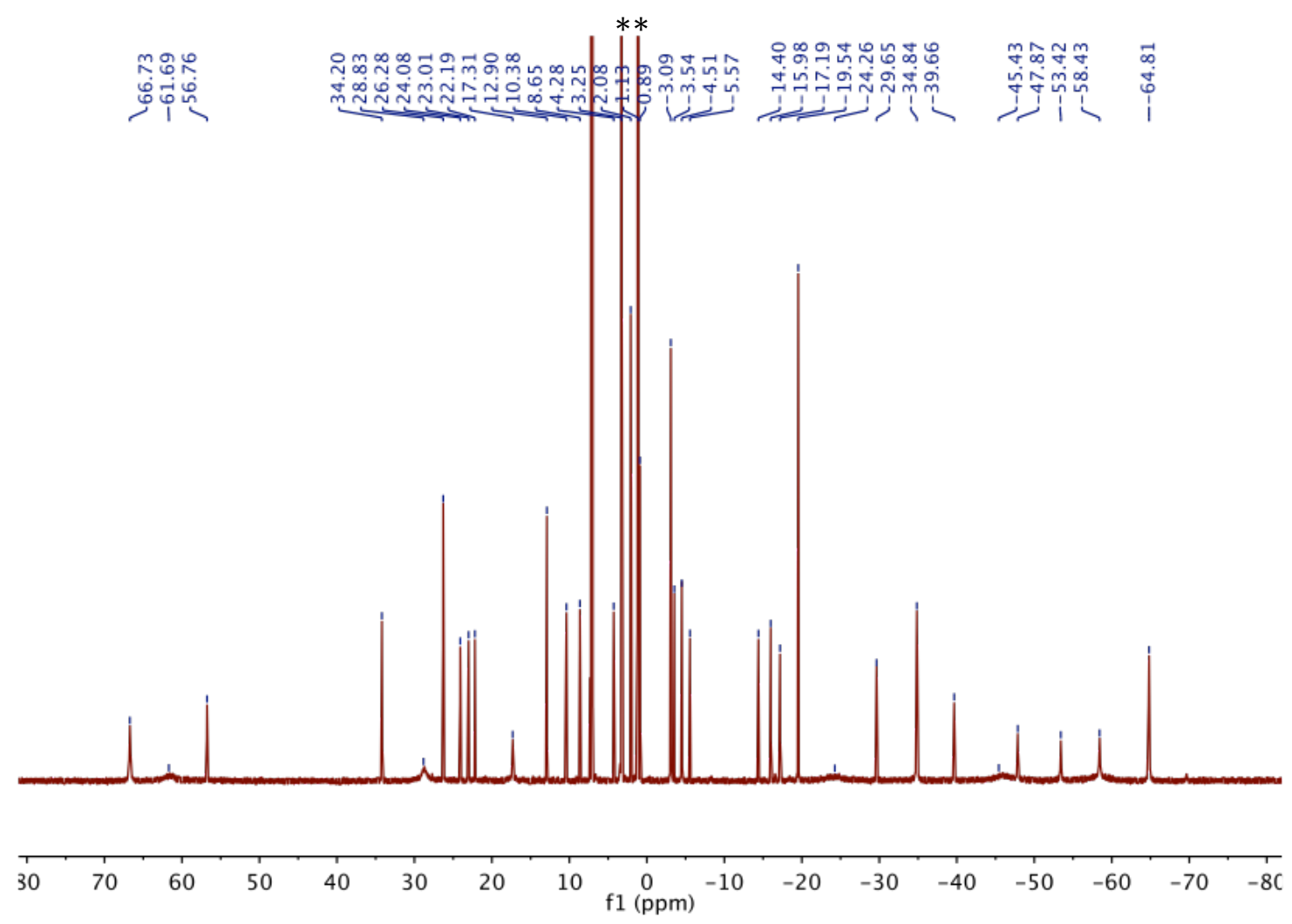

Figure S5. ${ }^{1} \mathrm{H}$ NMR spectrum of complex 3 in $\mathrm{C}_{6} \mathrm{D}_{6}$. Asterisks indicate the presence of $\mathrm{Et}_{2} \mathrm{O}$. 


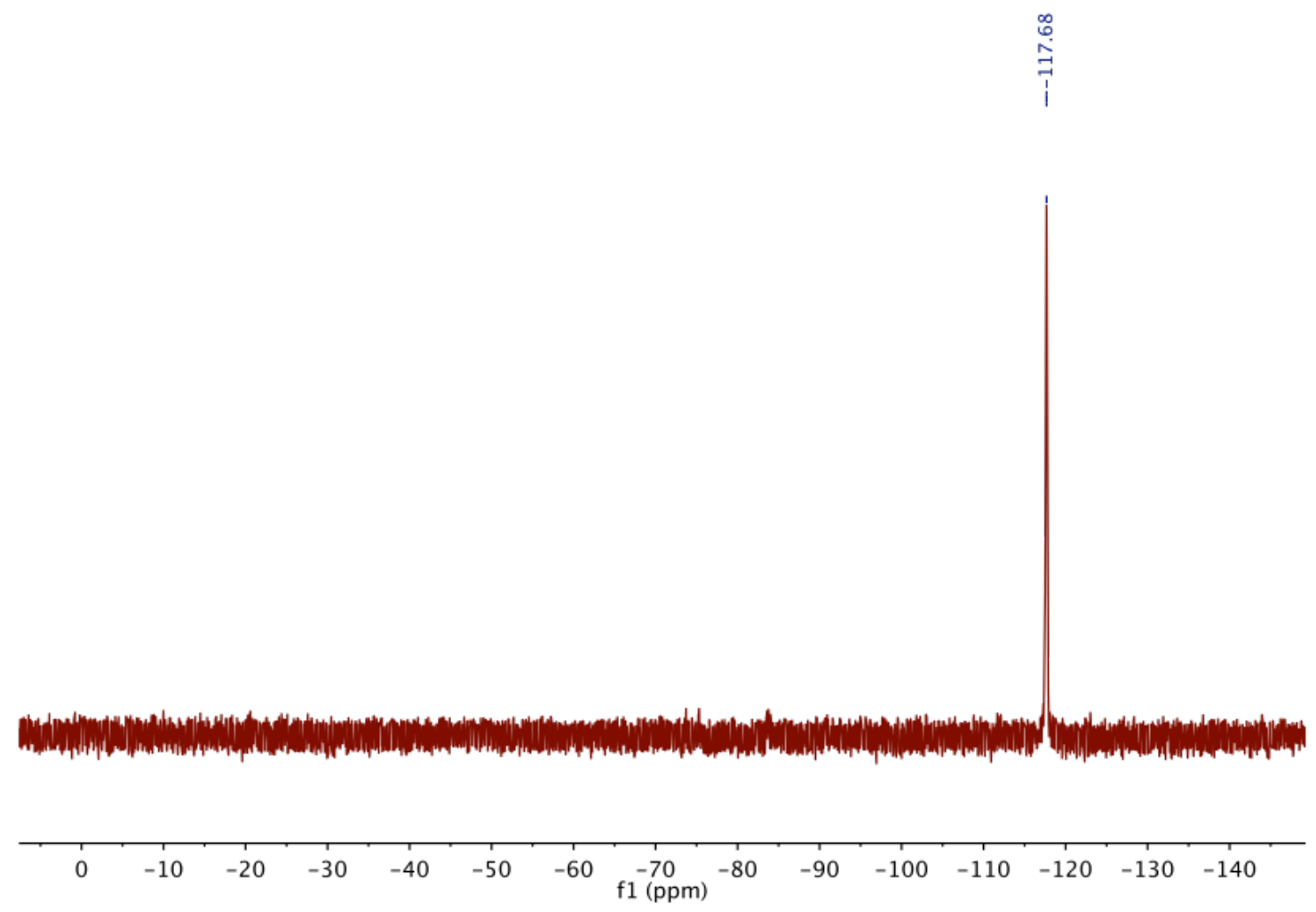

Figure S6. ${ }^{7} \mathrm{Li}\left\{{ }^{1} \mathrm{H}\right\}$ NMR spectrum of complex 3 in $\mathrm{C}_{6} \mathrm{D}_{6}$. 


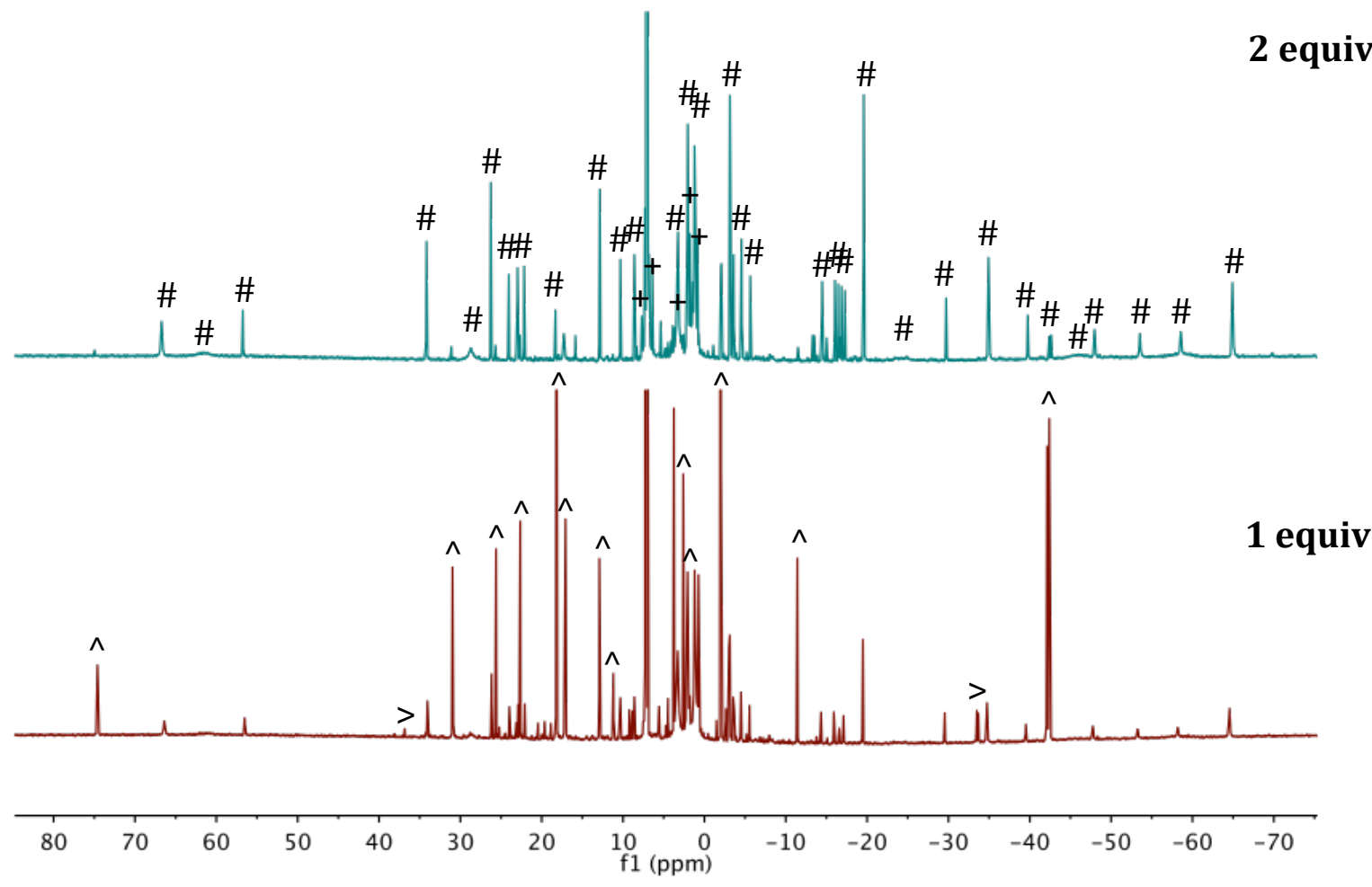

Figure S7. ${ }^{1} \mathrm{H}$ NMR spectra of the in situ reaction of 1 with 2 equiv of benzophenone in $\mathrm{C}_{6} \mathrm{D}_{6}$ at $25^{\circ} \mathrm{C}$. Experimental Details: A dark blue $\mathrm{C}_{6} \mathrm{D}_{6}$ solution $(1 \mathrm{~mL}$ ) containing 1 (19.9 mg, $0.025 \mathrm{mmol}$ ) was sealed in a J. Young NMR tube and the ${ }^{1} \mathrm{H}$ and ${ }^{7} \mathrm{Li}\left\{{ }^{1} \mathrm{H}\right\}$ NMR spectra were recorded. Then, 1 equiv of benzophenone ( $4.6 \mathrm{mg}, 0.025 \mathrm{mmol}$ ) in $\mathrm{C}_{6} \mathrm{D}_{6}(0.5 \mathrm{~mL})$ was added dropwise, resulting in a dark red solution. The tube was sealed and the ${ }^{1} \mathrm{H}$ and ${ }^{7} \mathrm{Li}\left\{{ }^{1} \mathrm{H}\right\}$ NMR spectra were recorded after standing at room temperature for $1 \mathrm{~h}$, which showed a mixture of $\mathbf{1}, \mathbf{3}$, and 2- $\mathrm{Li}-\mathrm{C}_{6} \mathrm{H}_{4} \mathrm{CH}_{2} \mathrm{NMe}_{2}$. Then, a second equiv of benzophenone $(5.0 \mathrm{mg}, 0.027 \mathrm{mmol})$ in $\mathrm{C}_{6} \mathrm{D}_{6}(0.5 \mathrm{~mL})$ was added dropwise, resulting in a lightening of the dark red solution to a dark red-orange. The tube was sealed and the ${ }^{1} \mathrm{H}$ and ${ }^{7} \mathrm{Li}\left\{{ }^{1} \mathrm{H}\right\}$ NMR spectra were recorded after standing at room temperature for $1 \mathrm{~h}$, which showed the complete consumption of $1{ }^{\wedge}$ indicates resonances assignable to complex 1, > indicates resonances assignable to the impurity present in complex 1, \# indicates the resonances assignable to complex 3 , and + indicates the resonances assignable to $2-\mathrm{Li}_{-} \mathrm{C}_{6} \mathrm{H}_{4} \mathrm{CH}_{2} \mathrm{NMe}_{2}(7.70,4.46,2.79$, $1.77,0.84 \mathrm{ppm}) .^{1}$ 

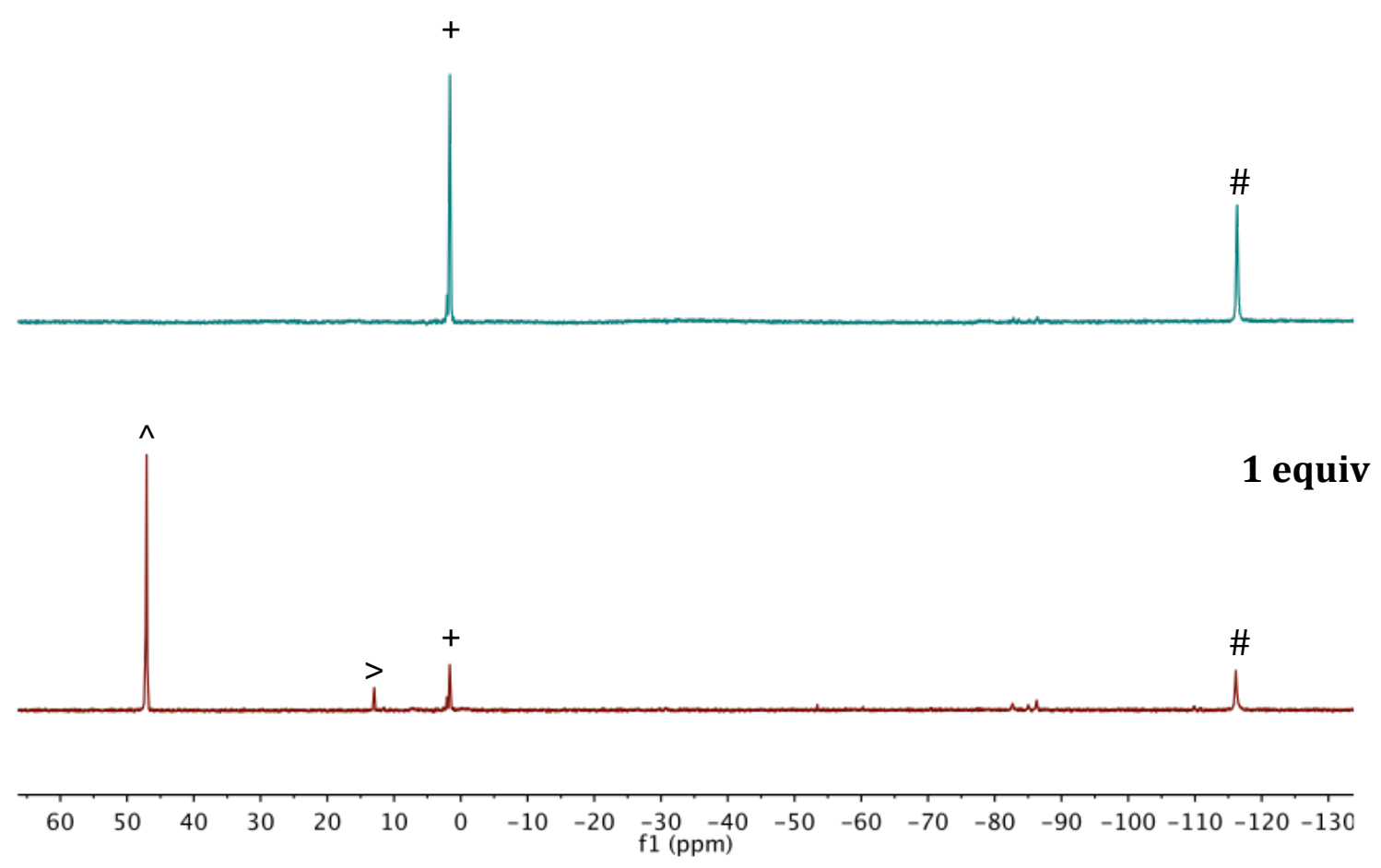

Figure S8. ${ }^{7} \mathrm{Li}\left\{{ }^{1} \mathrm{H}\right\}$ NMR spectra of the in situ reaction of 1 with 2 equiv of benzophenone in $\mathrm{C}_{6} \mathrm{D}_{6}$ at $25{ }^{\circ} \mathrm{C}$. Experimental Details: See Figure S7. ${ }^{\wedge}$ indicates resonances assignable to complex 1, > indicates resonances assignable to the impurity present in complex $\mathbf{1}$, \# indicates the resonance assignable to complex $\mathbf{3}$, and + indicates the resonance assignable to $2-\mathrm{Li}_{-} \mathrm{C}_{6} \mathrm{H}_{4} \mathrm{CH}_{2} \mathrm{NMe}_{2}$. 

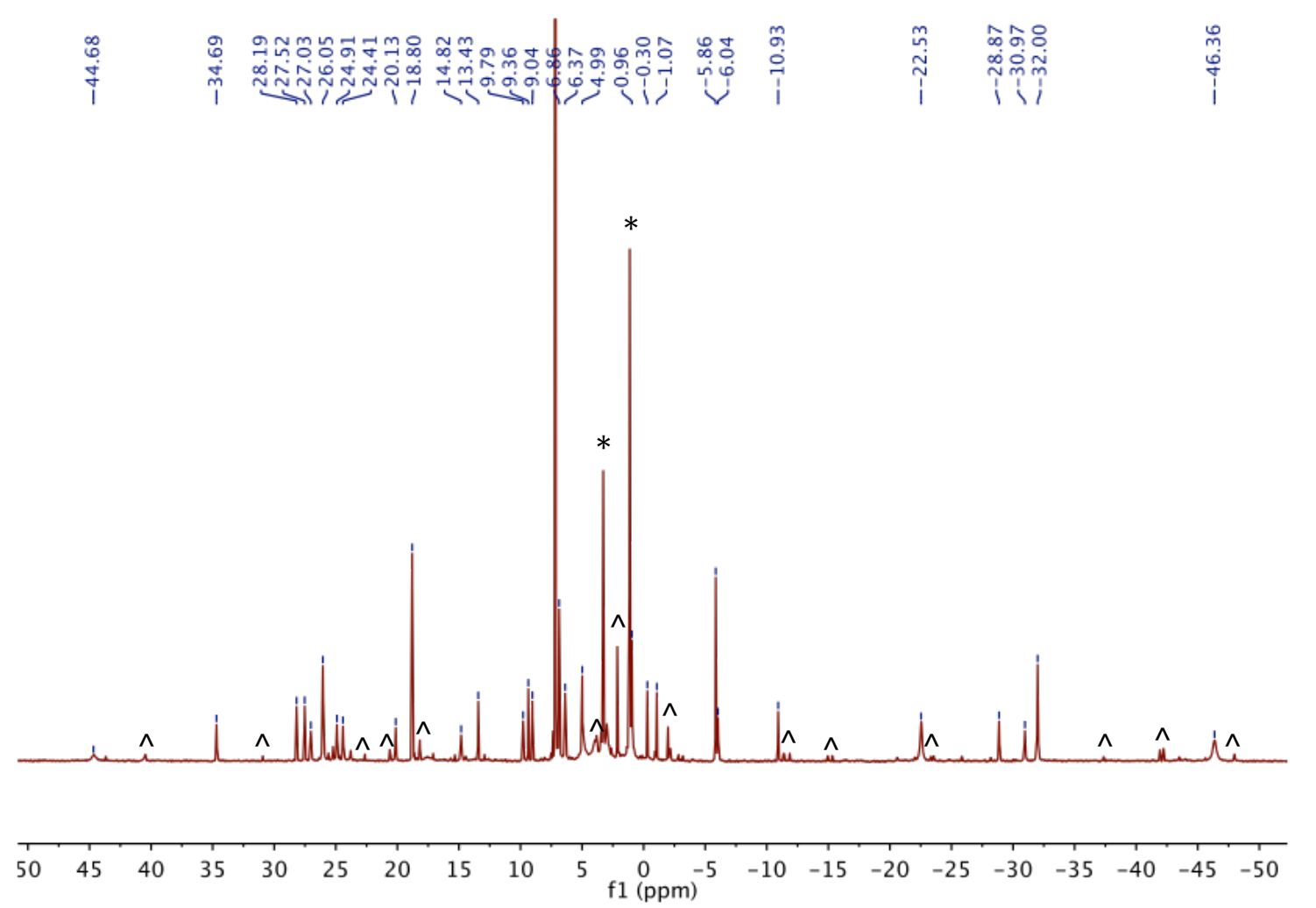

Figure S9. ${ }^{1} \mathrm{H}$ NMR spectrum of complex 4 in $\mathrm{C}_{6} \mathrm{D}_{6}$. Asterisks indicate the presence of $\mathrm{Et}_{2} \mathrm{O}$, and ${ }^{\wedge}$ indicates resonances assigned to an unidentified impurity. 


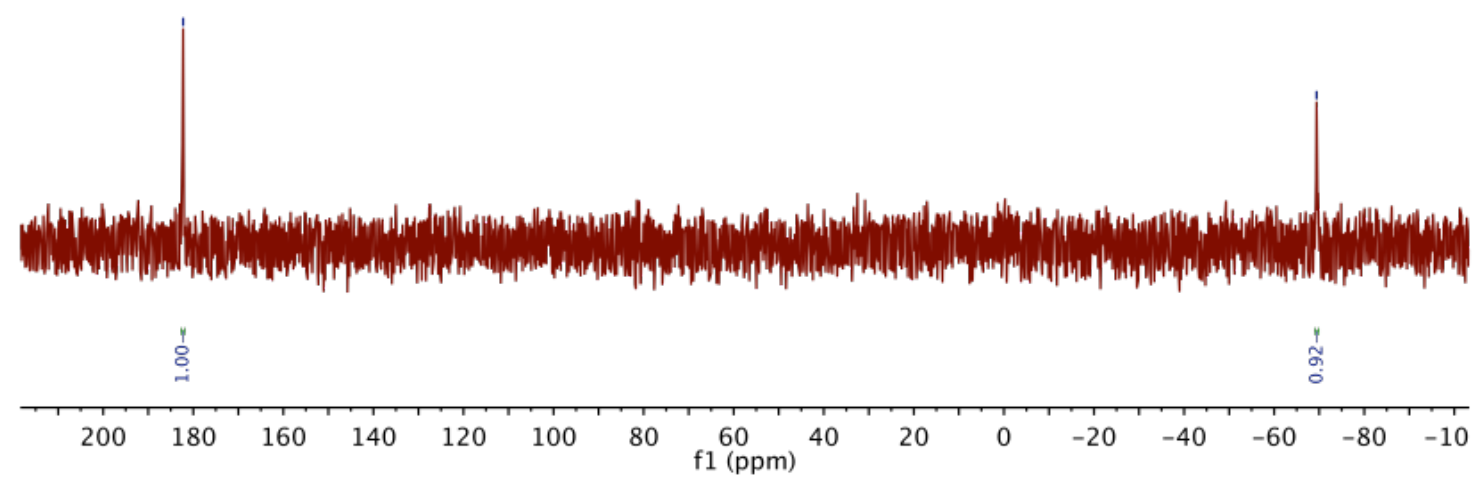

Figure S10. ${ }^{7} \mathrm{Li}\left\{{ }^{1} \mathrm{H}\right\}$ NMR spectrum of complex 4 in $\mathrm{C}_{6} \mathrm{D}_{6}$. 

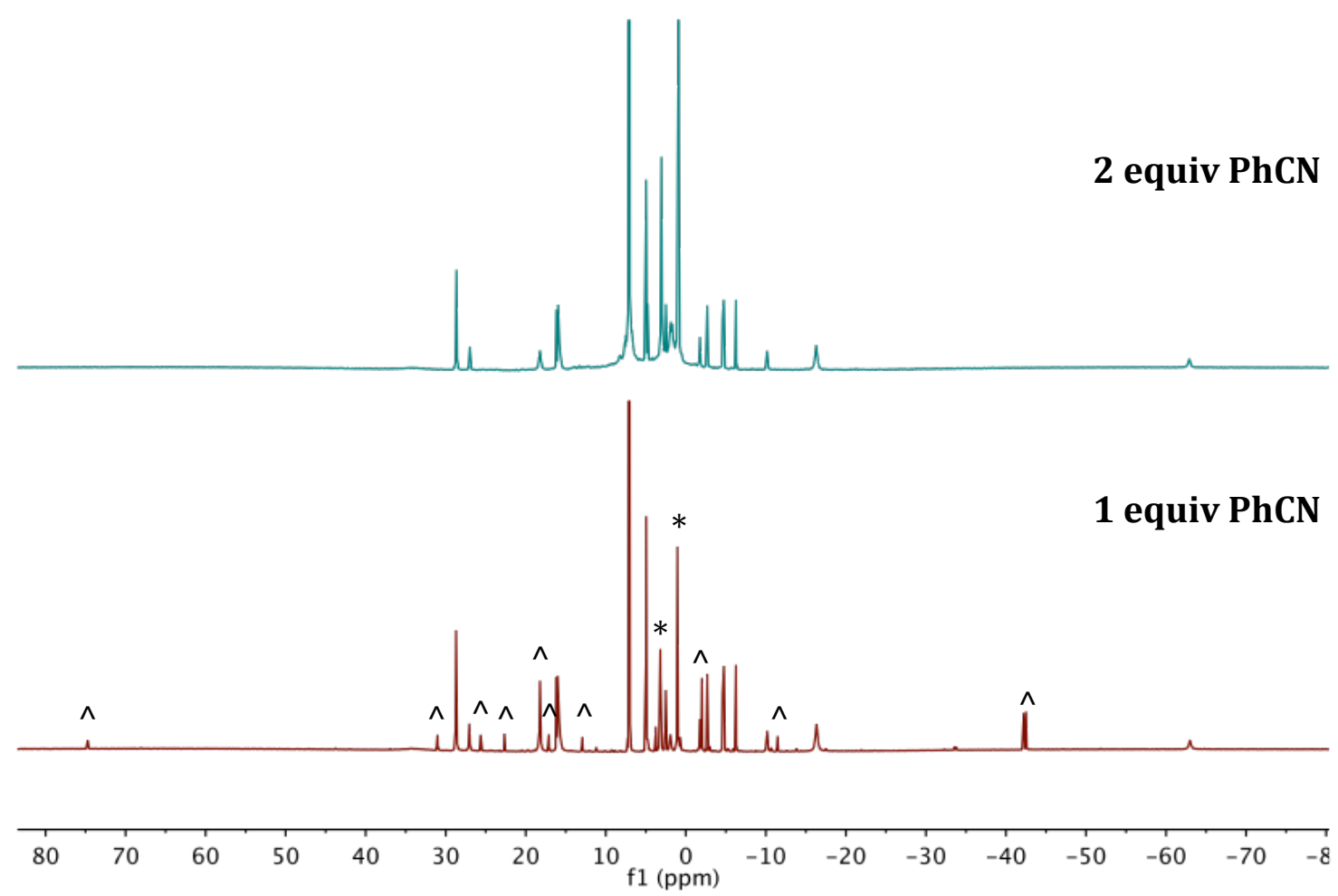

Figure S11. ${ }^{1} \mathrm{H}$ NMR spectra of the in situ reaction of 1 with 2 equiv of $\mathrm{PhCN}_{\text {in }} \mathrm{C}_{6} \mathrm{D}_{6}$ at $25^{\circ} \mathrm{C}$. Experimental Details: A dark blue $\mathrm{C}_{6} \mathrm{D}_{6}$ solution $(1 \mathrm{~mL})$ containing 1 (23.9 $\mathrm{mg}, 0.030 \mathrm{mmol}$ ) was sealed in a J. Young NMR tube and the ${ }^{1} \mathrm{H}$ and ${ }^{7} \mathrm{Li}\left\{{ }^{1} \mathrm{H}\right\}$ NMR spectra were recorded. Then, 1 equiv of PhCN (3.5 $\mu \mathrm{L}, 0.034 \mathrm{mmol})$ was added via microsyringe, resulting in a dark green-brown solution. The tube was sealed and the ${ }^{1} \mathrm{H}$ and ${ }^{7} \mathrm{Li}\left\{{ }^{1} \mathrm{H}\right\}$ NMR spectra were recorded after standing at room temperature for 1 h, which showed a mixture of $\mathbf{1}$ and a new paramagnetic product. Then, a second equiv of PhCN (3.5 $\mu \mathrm{L}, 0.034 \mathrm{mmol})$ was added dropwise, resulting in no visible color change. The tube was sealed and the ${ }^{1} \mathrm{H}$ and ${ }^{7} \mathrm{Li}\left\{{ }^{1} \mathrm{H}\right\}$ NMR spectra were recorded after standing at room temperature for $1 \mathrm{~h}$, which showed the complete consumption of $\mathbf{1}$. Asterisks indicate the presence of $\mathrm{Et}_{2} \mathrm{O}$, and ${ }^{\wedge}$ indicates resonances assignable to complex $\mathbf{1}$. 


\section{2 equiv PhCN}
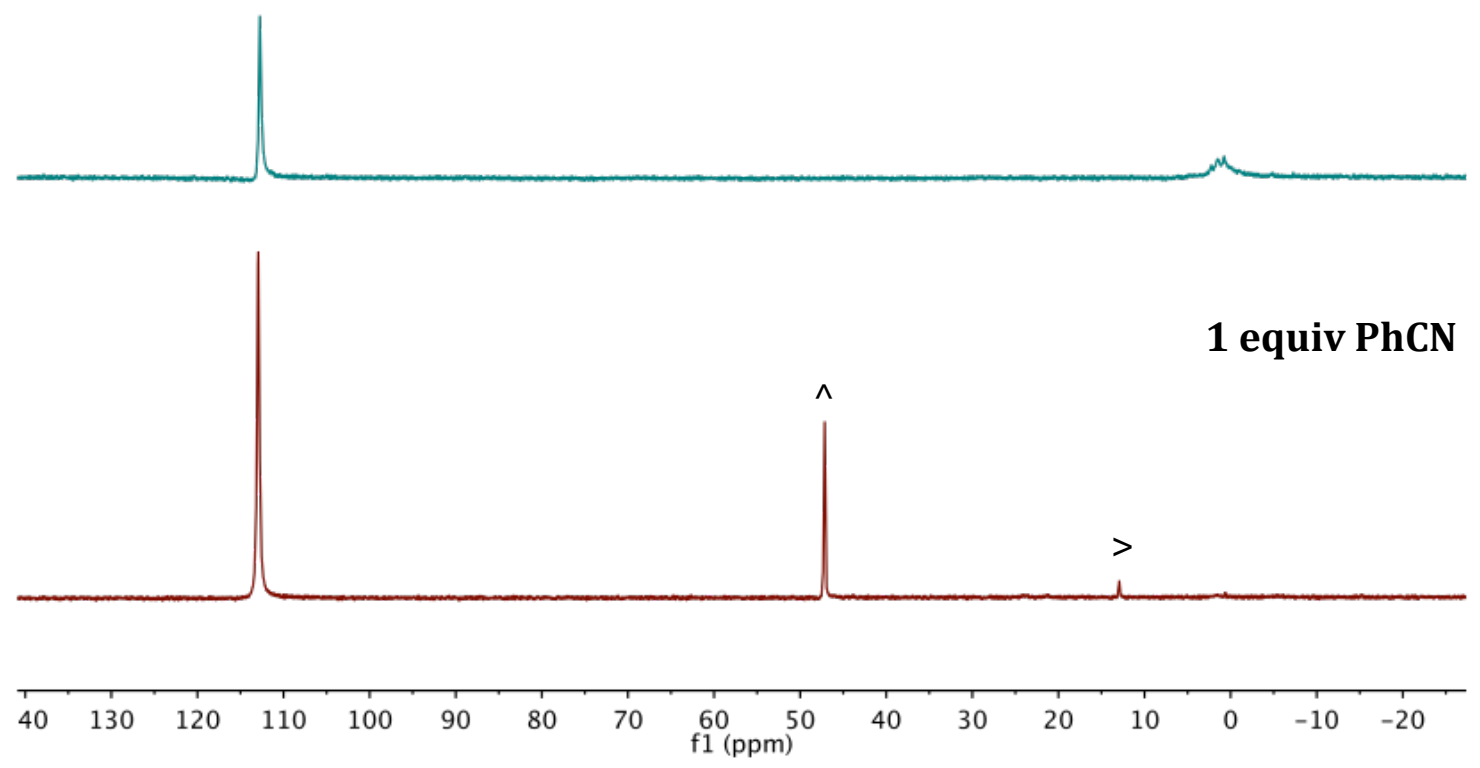

Figure S12. ${ }^{7} \mathrm{Li}\left\{{ }^{1} \mathrm{H}\right\}$ NMR spectra of the in situ reaction of 1 with 2 equiv of PhCN in $\mathrm{C}_{6} \mathrm{D}_{6}$ at $25^{\circ} \mathrm{C}$. Experimental Details: See Figure S11. ${ }^{\wedge}$ indicates the resonance assignable to complex $\mathbf{1}$, and > indicates the resonance assignable to the impurity present in complex $\mathbf{1}$. 


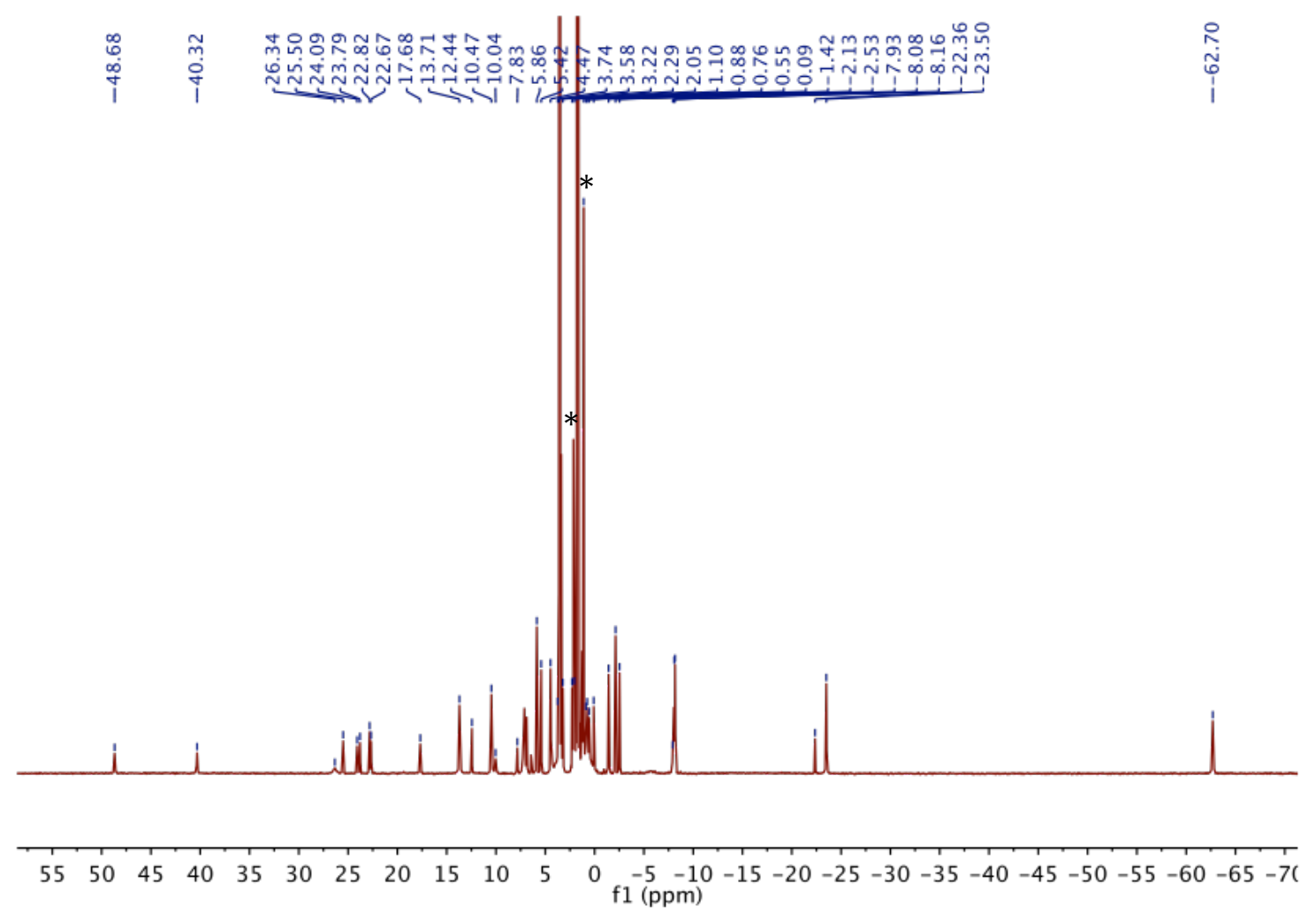

Figure S13. ${ }^{1} \mathrm{H}$ NMR spectrum of complex 5 in THF- $d_{8}$. Asterisks indicate the presence of $\mathrm{Et}_{2} \mathrm{O}$. 


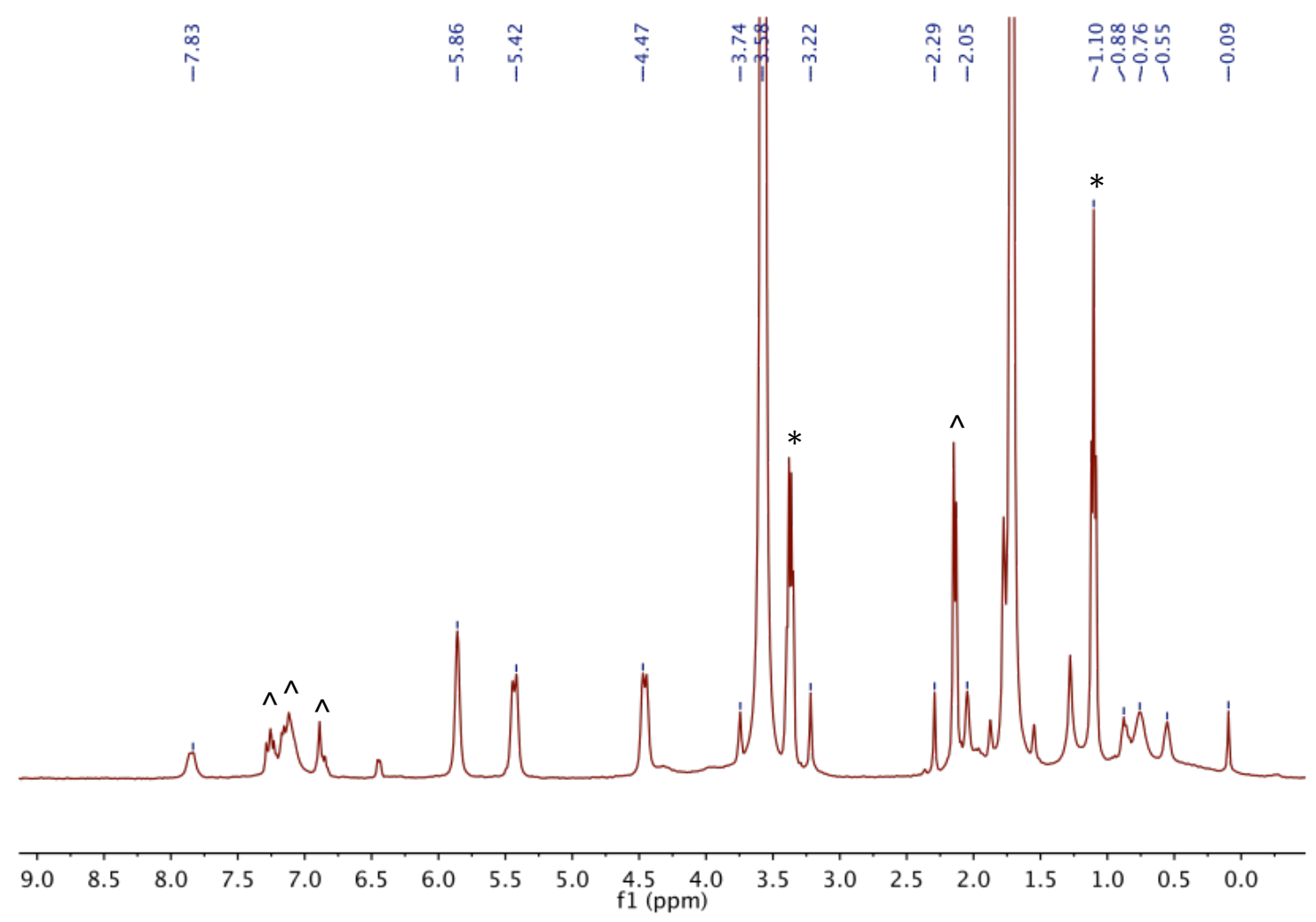

Figure S14. Partial ${ }^{1} \mathrm{H}$ NMR spectrum of complex 5 in THF- $d_{8}{ }^{\wedge}$ indicates the presence of free dimethylbenzylamine and asterisks indicate the presence of $\mathrm{Et}_{2} \mathrm{O}$. 

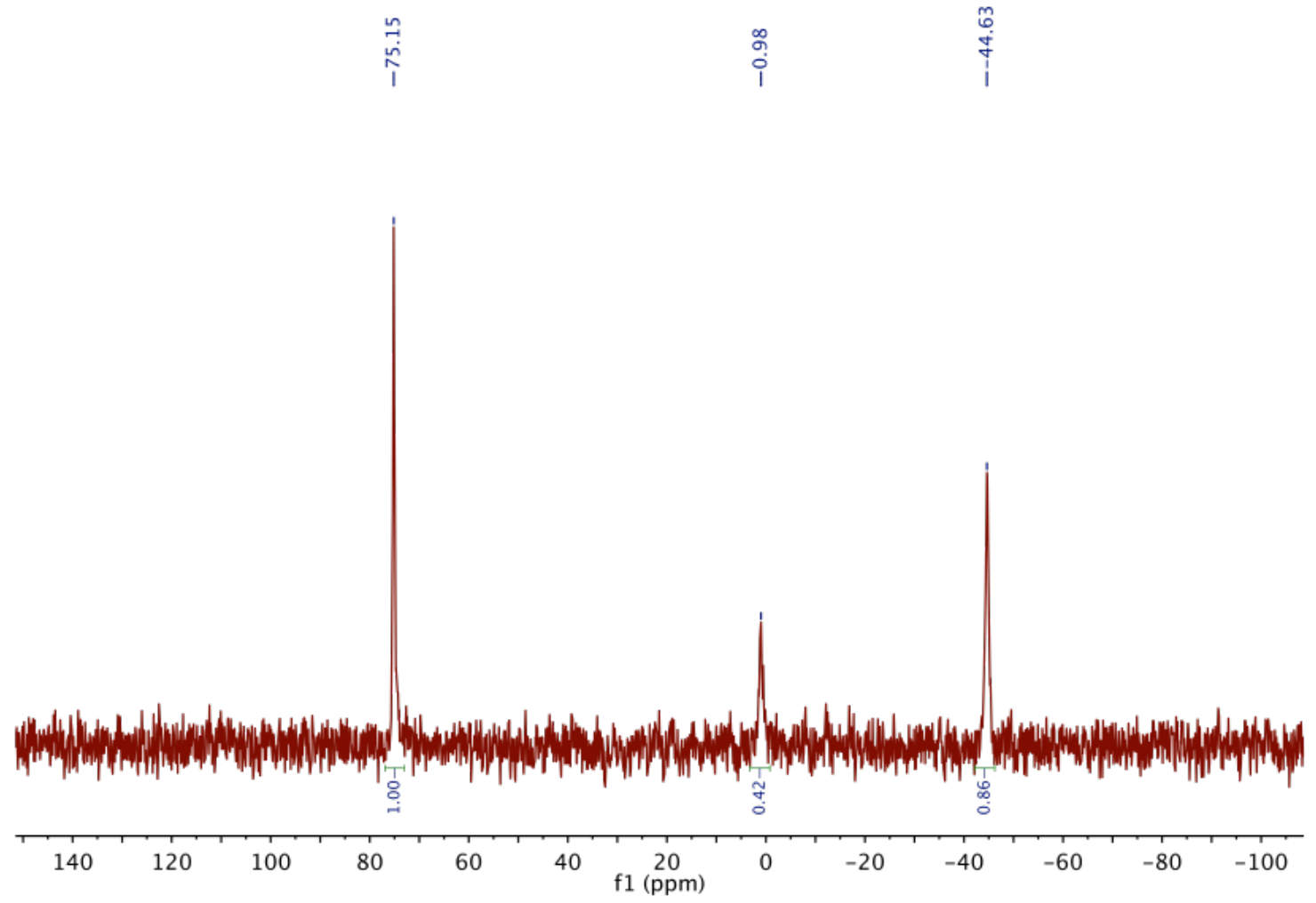

Figure S15. ${ }^{7} \mathrm{Li}\left\{{ }^{1} \mathrm{H}\right\}$ NMR spectrum of complex 5 in THF- $d_{8}$. 


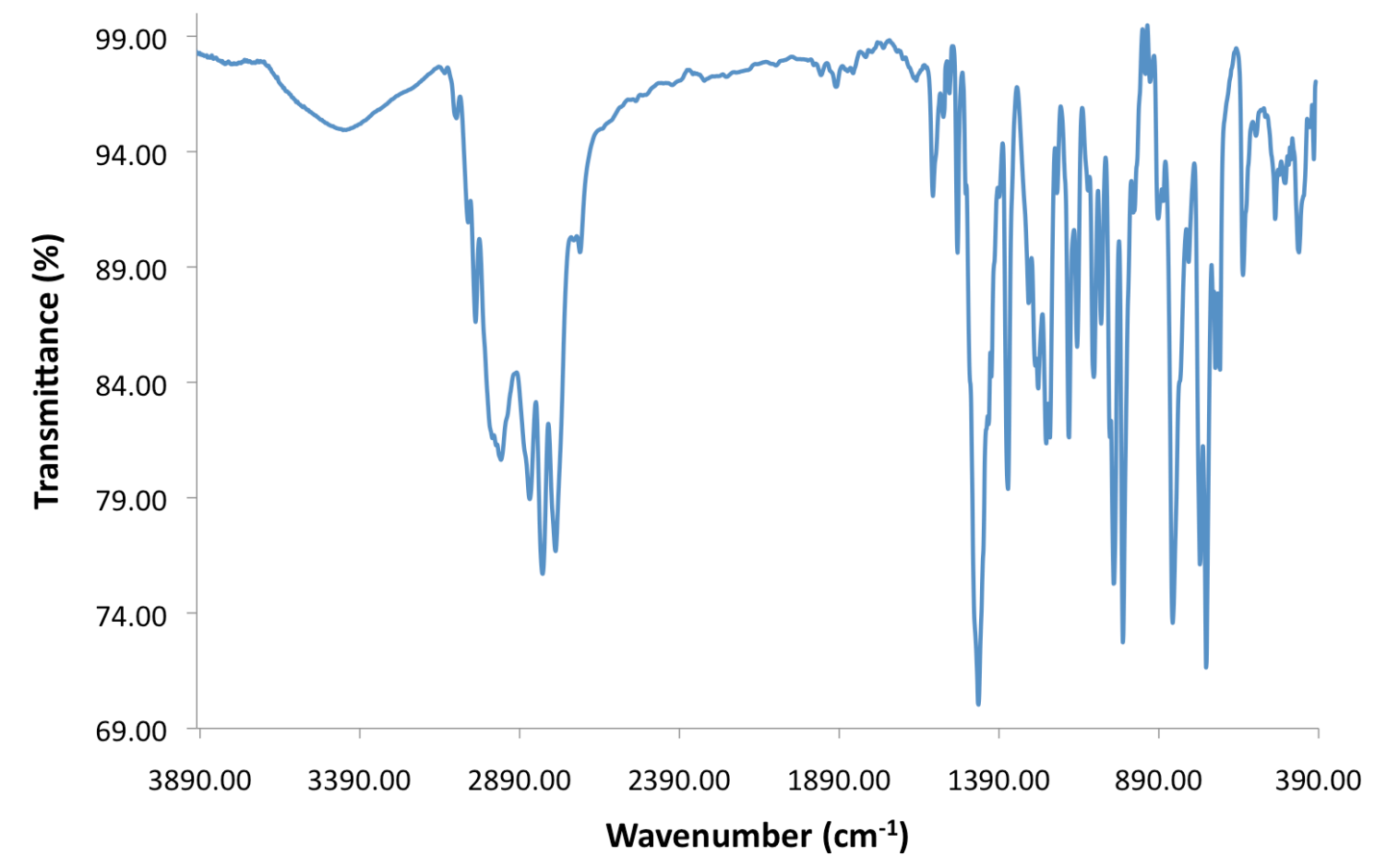

Figure S16. IR spectrum of complex $\mathbf{1}$ (as a $\mathrm{KBr}$ pellet).

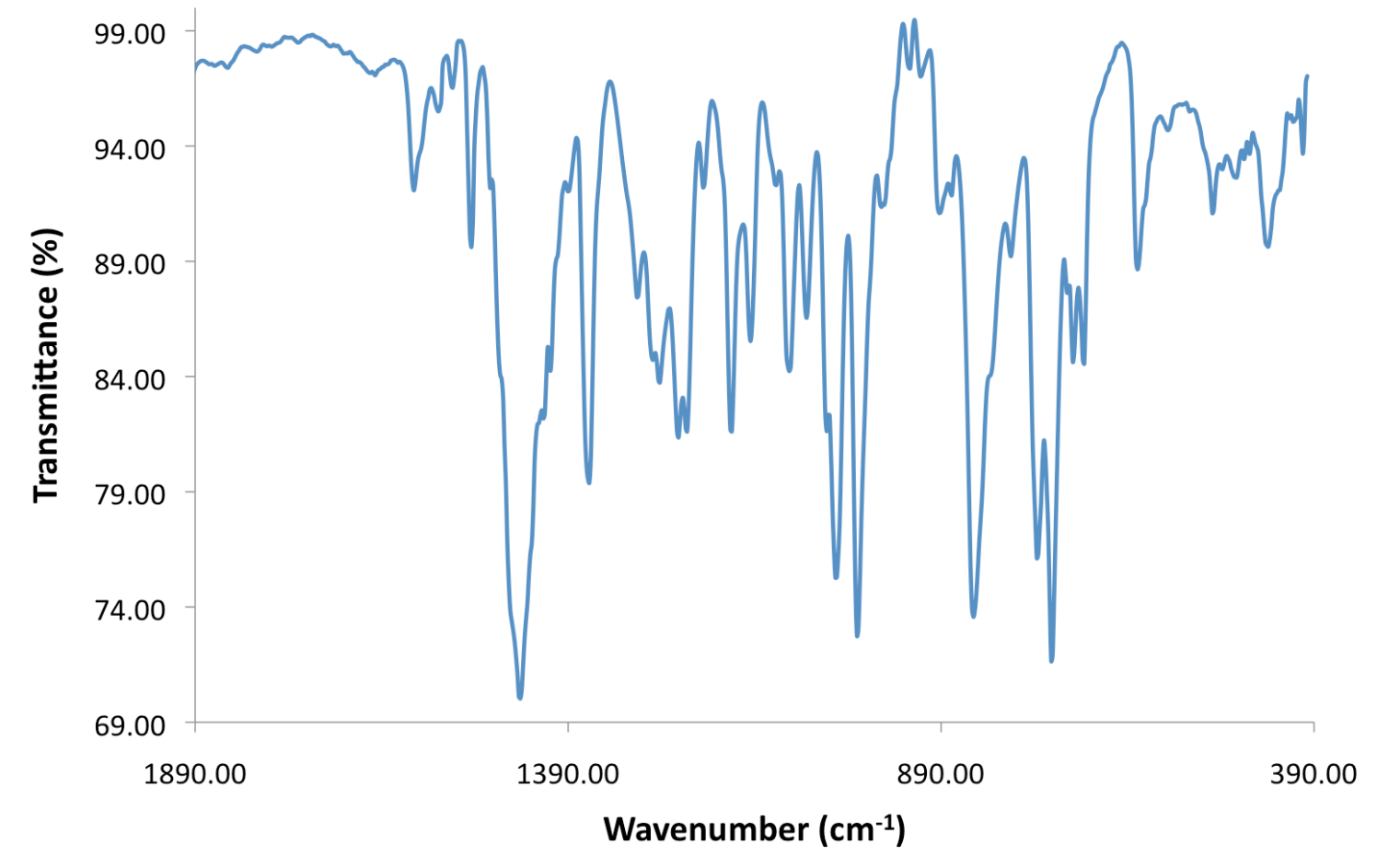

Figure S17. Partial IR spectrum of complex 1 (as a KBr pellet). 


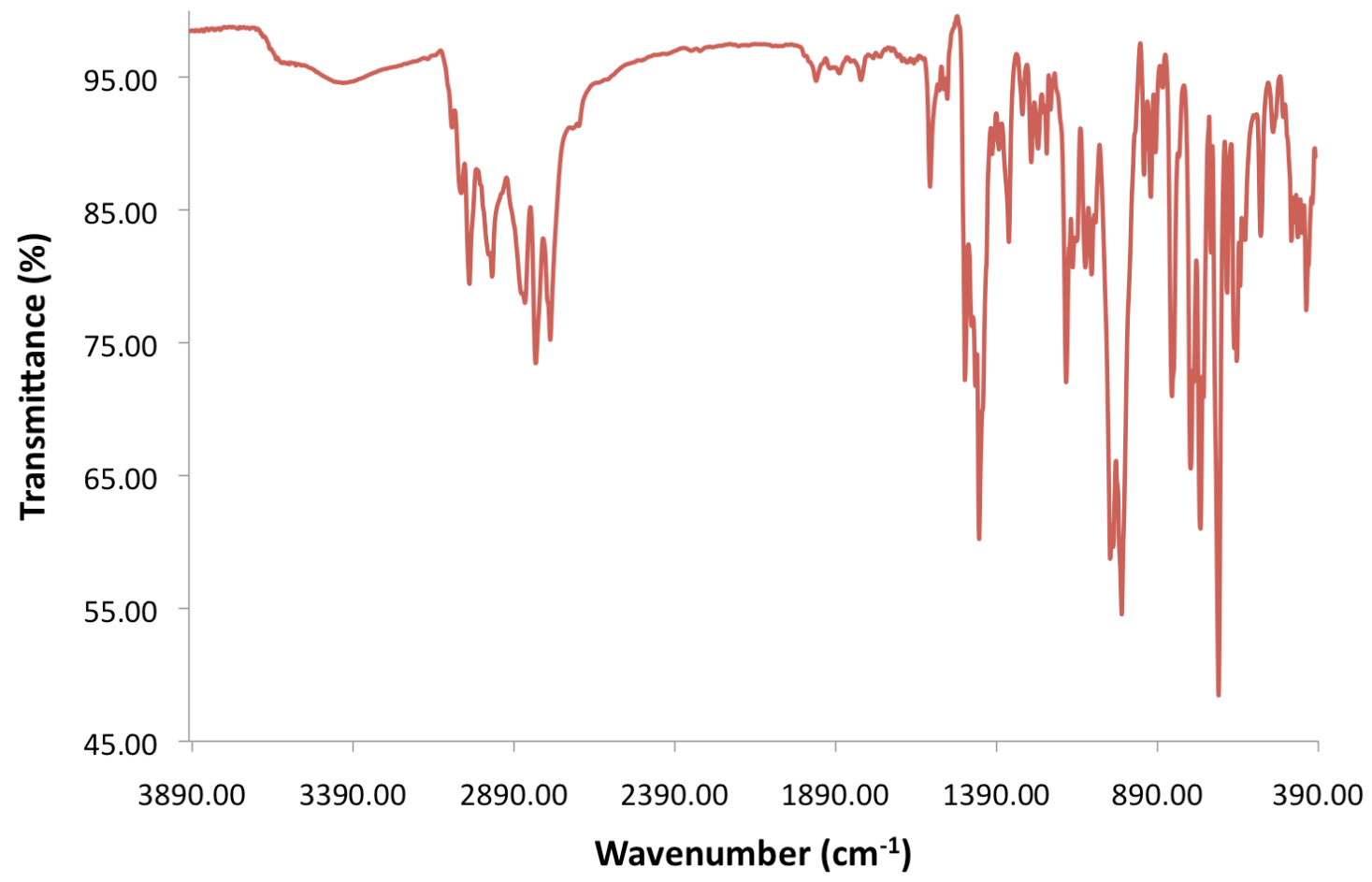

Figure S18. IR spectrum of complex 3 (as a $\mathrm{KBr}$ pellet).

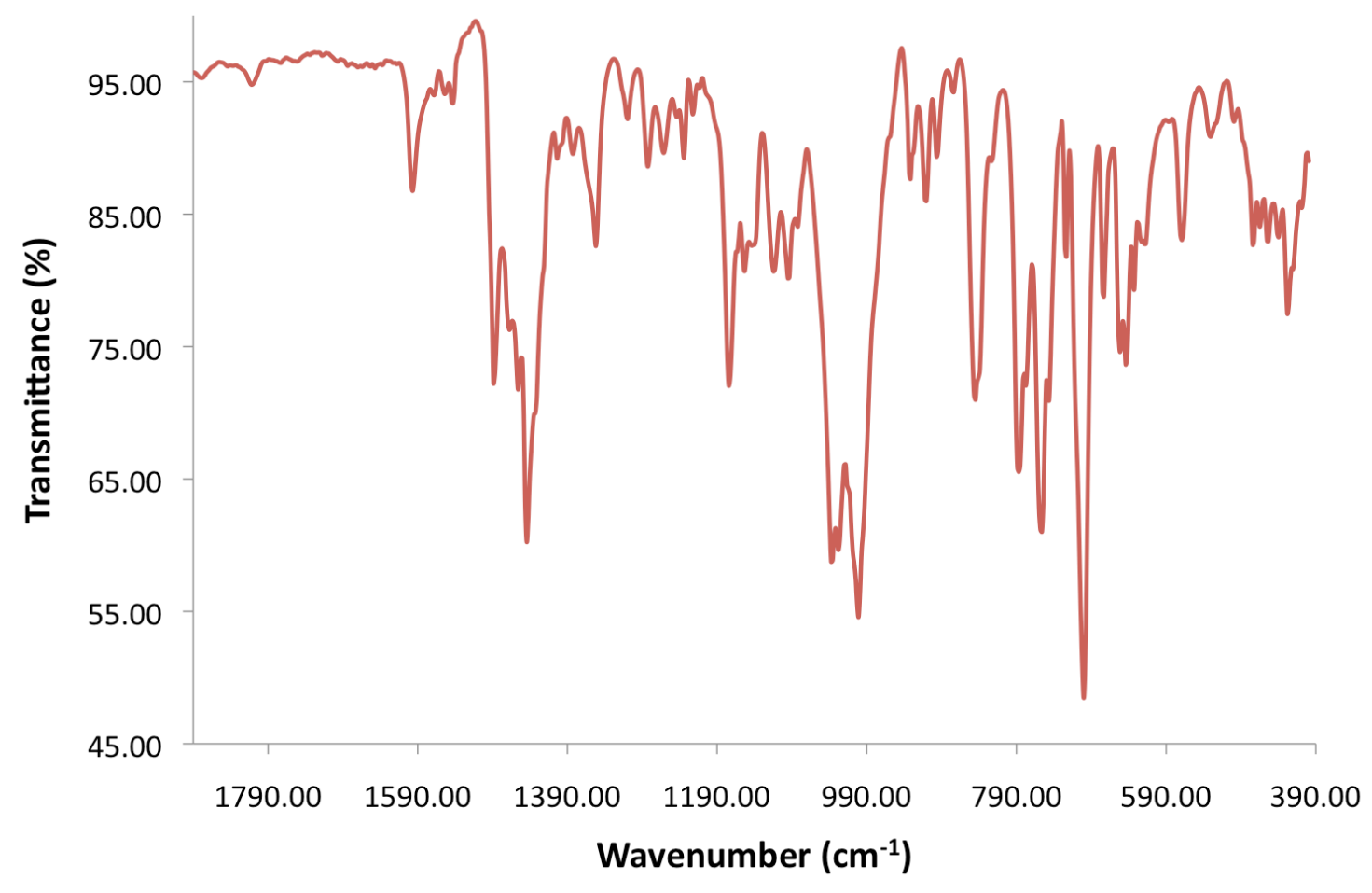

Figure S19. Partial IR spectrum of complex 3 (as a $\mathrm{KBr}$ pellet). 


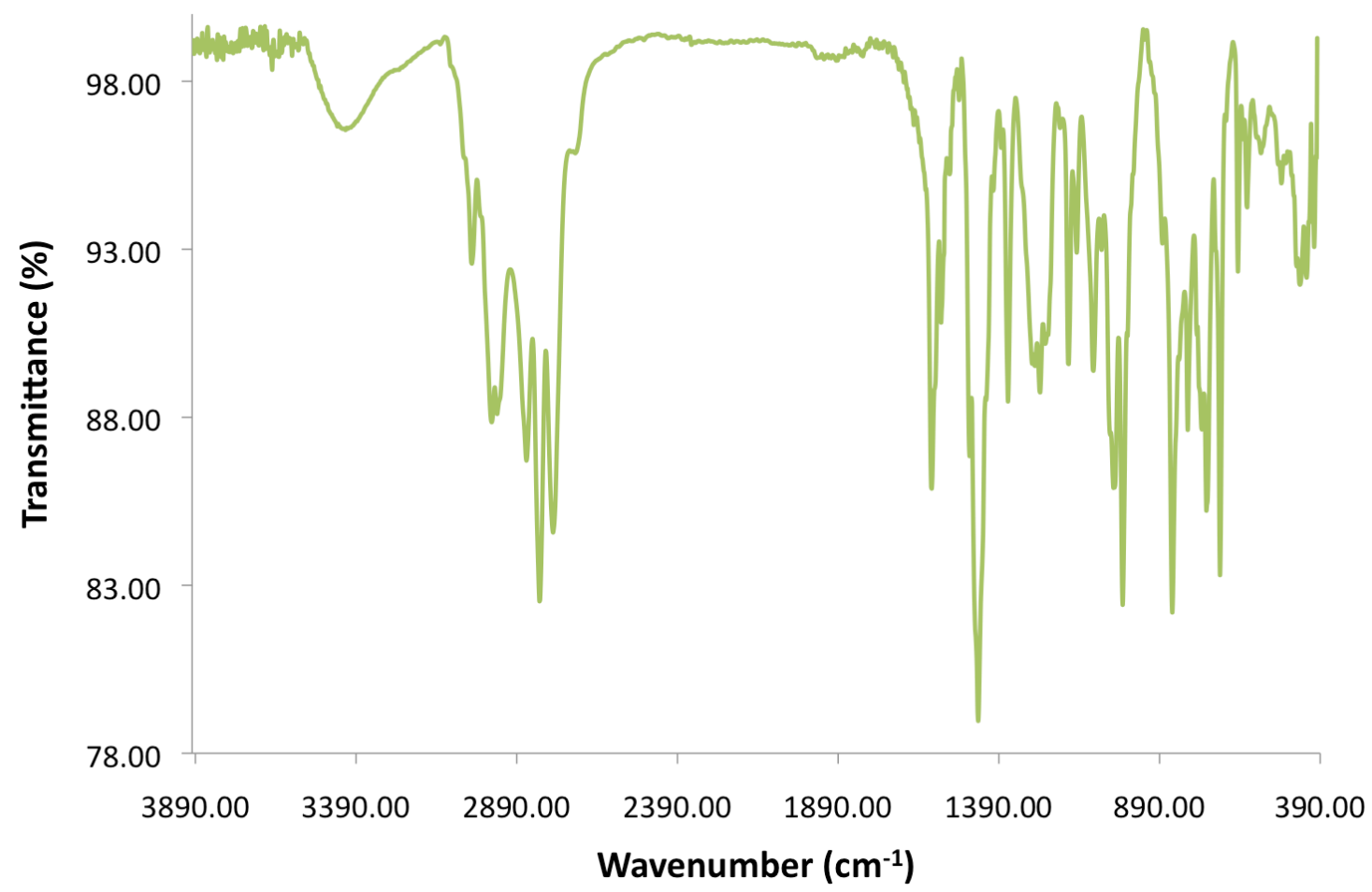

Figure S20. IR spectrum of complex 4 (as a $\mathrm{KBr}$ pellet).

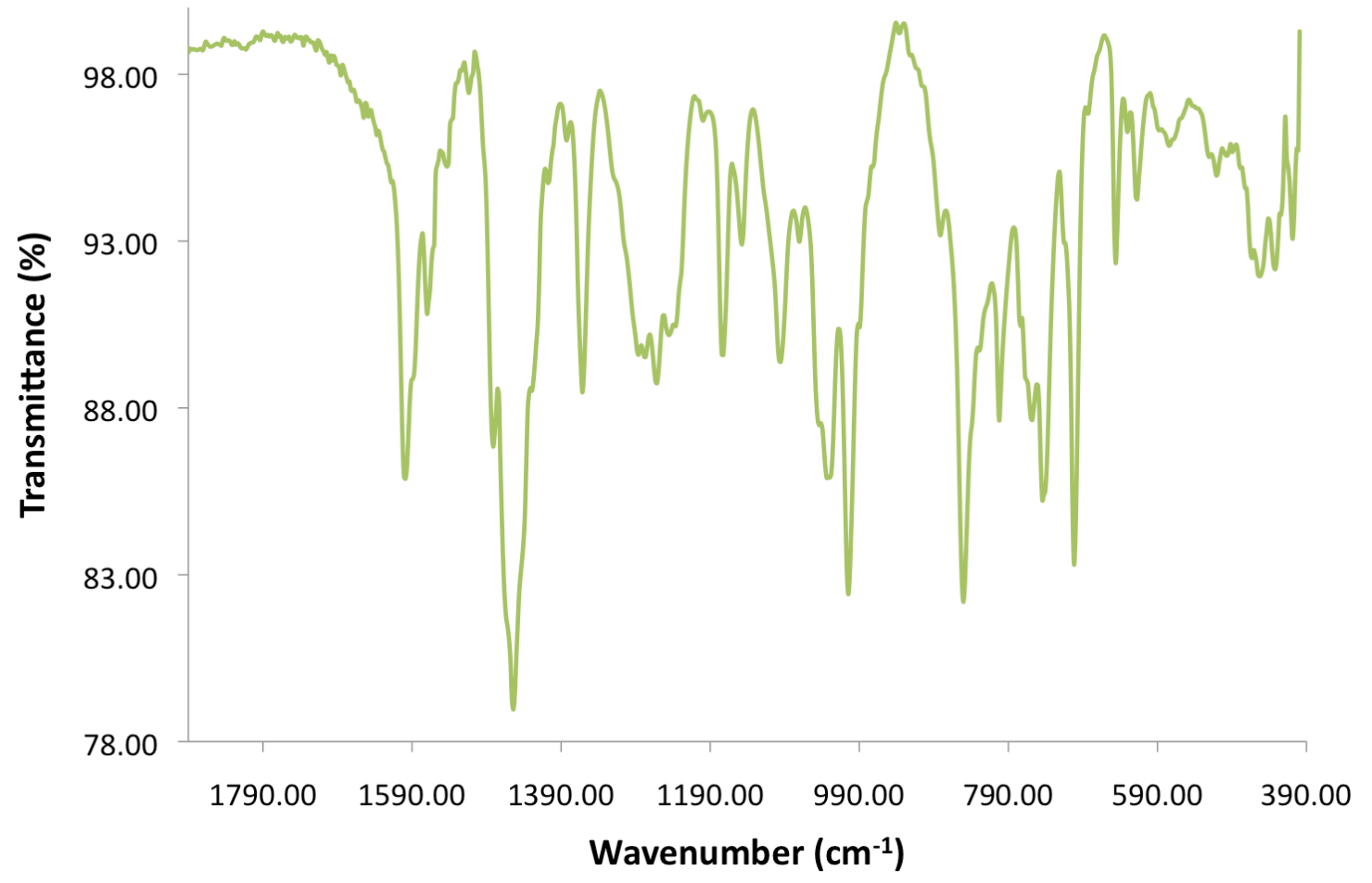

Figure S21. Partial IR spectrum of complex 4 (as a KBr pellet). 


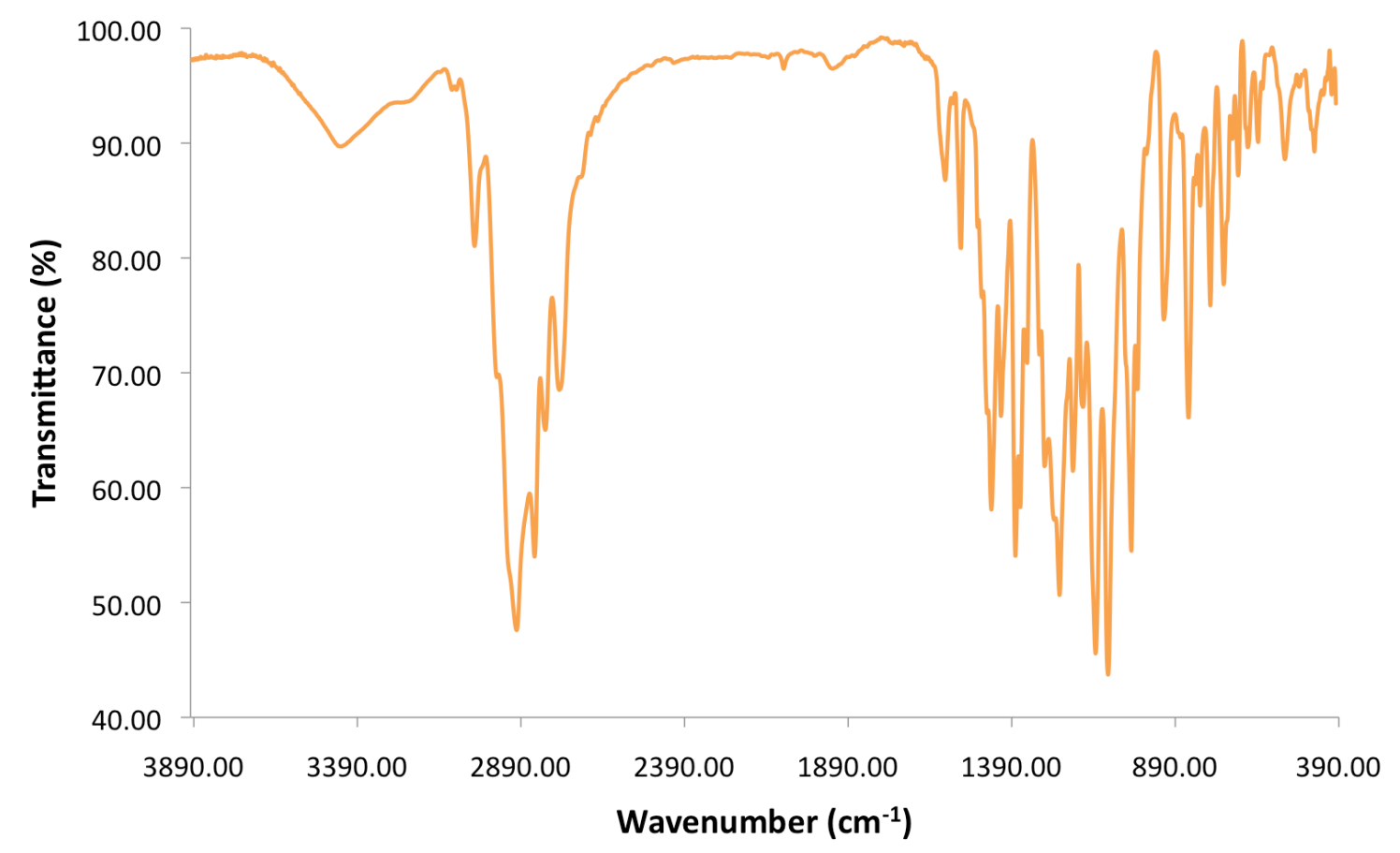

Figure S22. IR spectrum of complex $\mathbf{5}$ (as a $\mathrm{KBr}$ pellet).

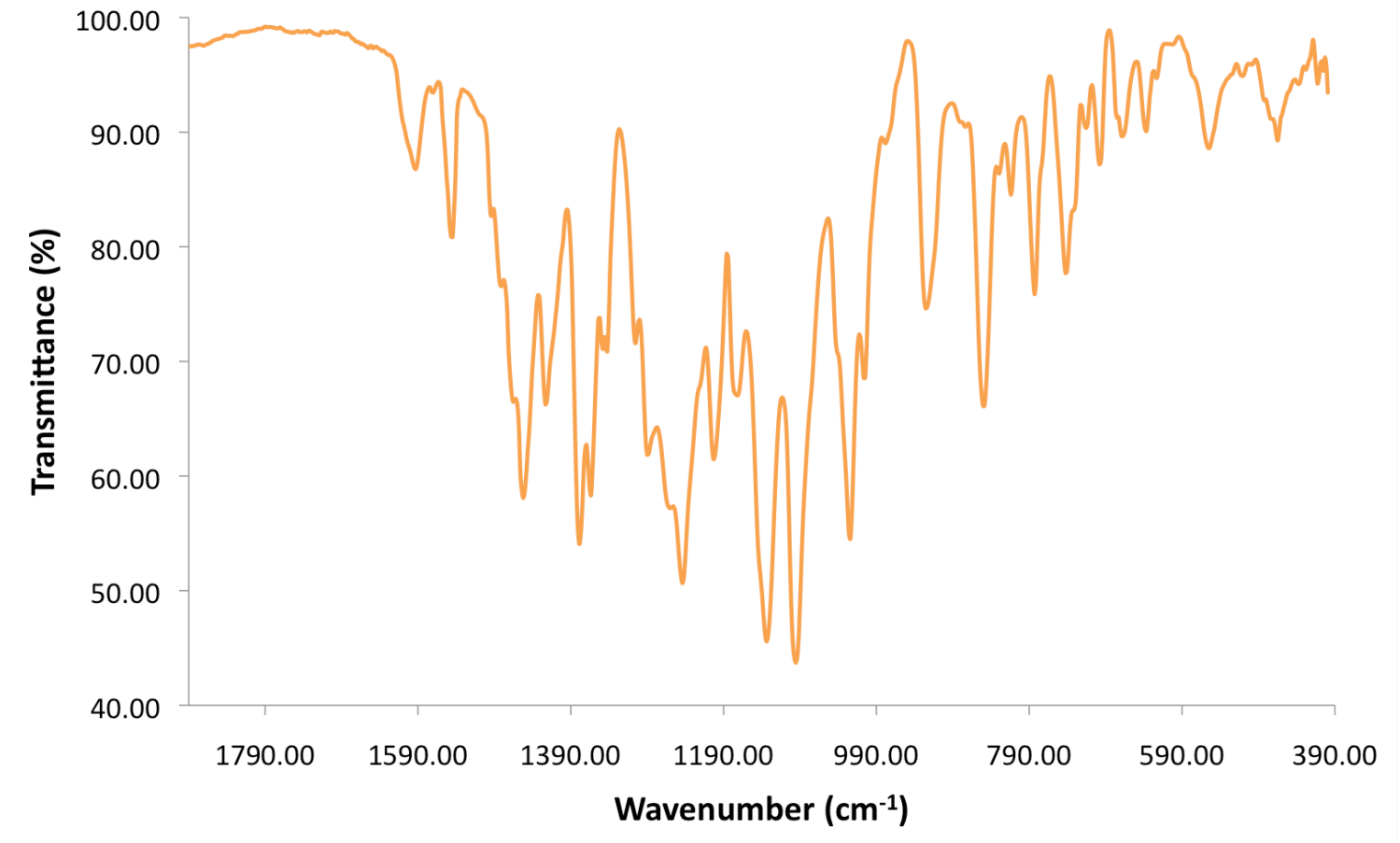

Figure S23. Partial IR spectrum of complex $\mathbf{5}$ (as a KBr pellet). 


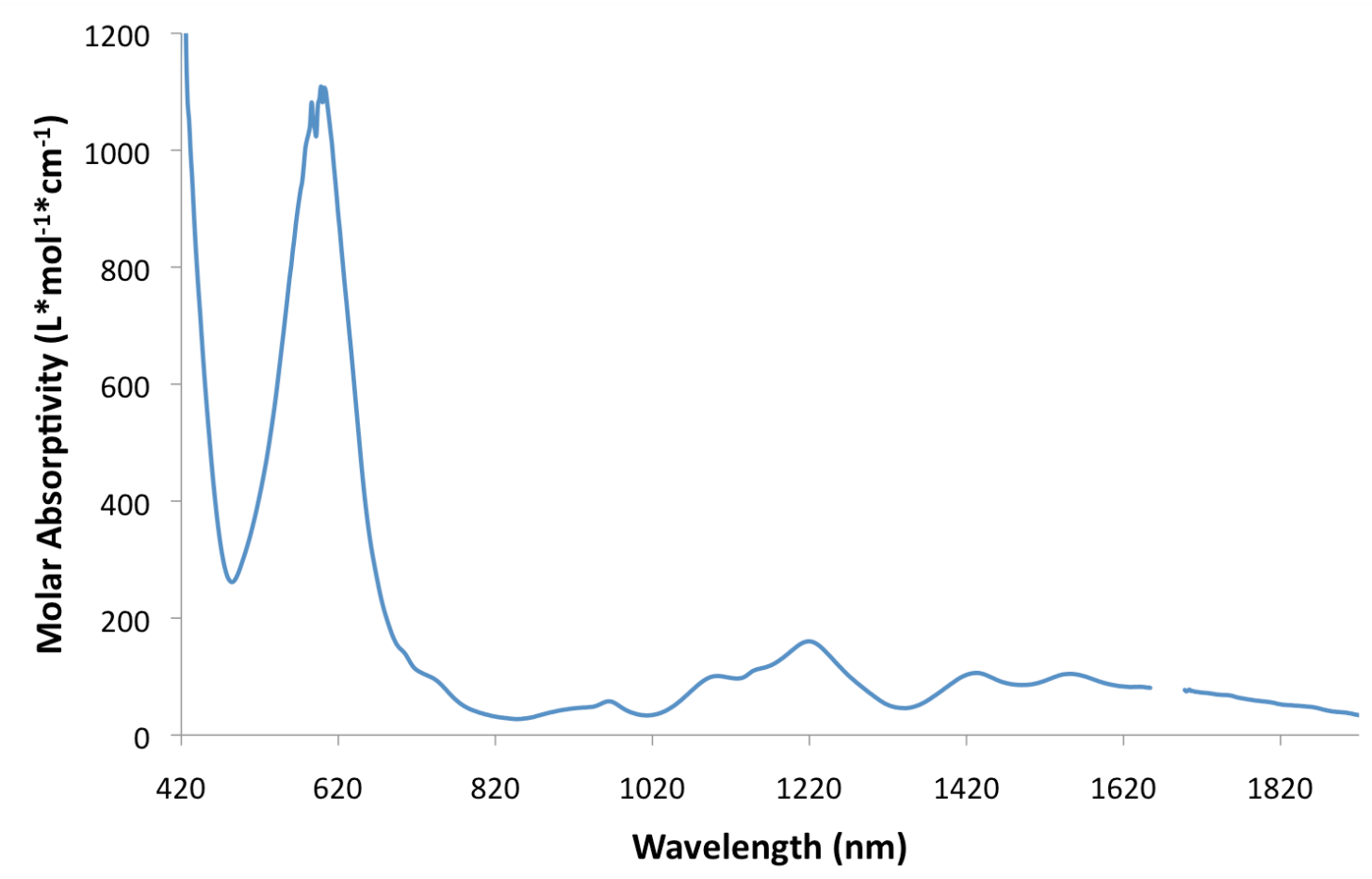

Figure S24. UV-vis/NIR spectrum of complex $1\left(\mathrm{C}_{6} \mathrm{H}_{6}, 4.19 \times 10^{-3} \mathrm{M}\right)$. Solvent absorption has been removed for clarity.

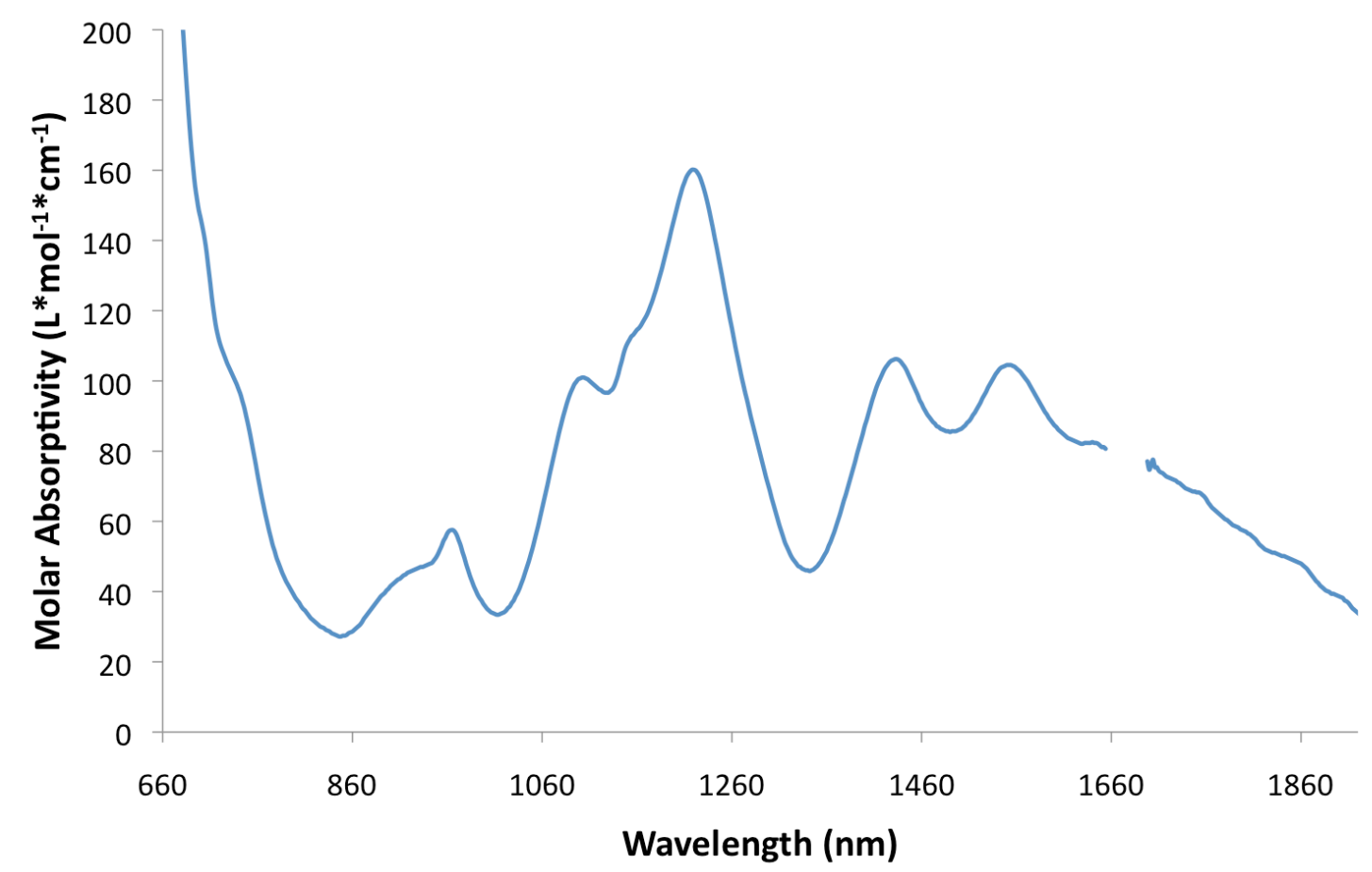

Figure S25. Partial UV-vis/NIR spectrum of complex $1\left(\mathrm{C}_{6} \mathrm{H}_{6}, 4.19 \times 10^{-3} \mathrm{M}\right)$. Solvent absorption has been removed for clarity. 


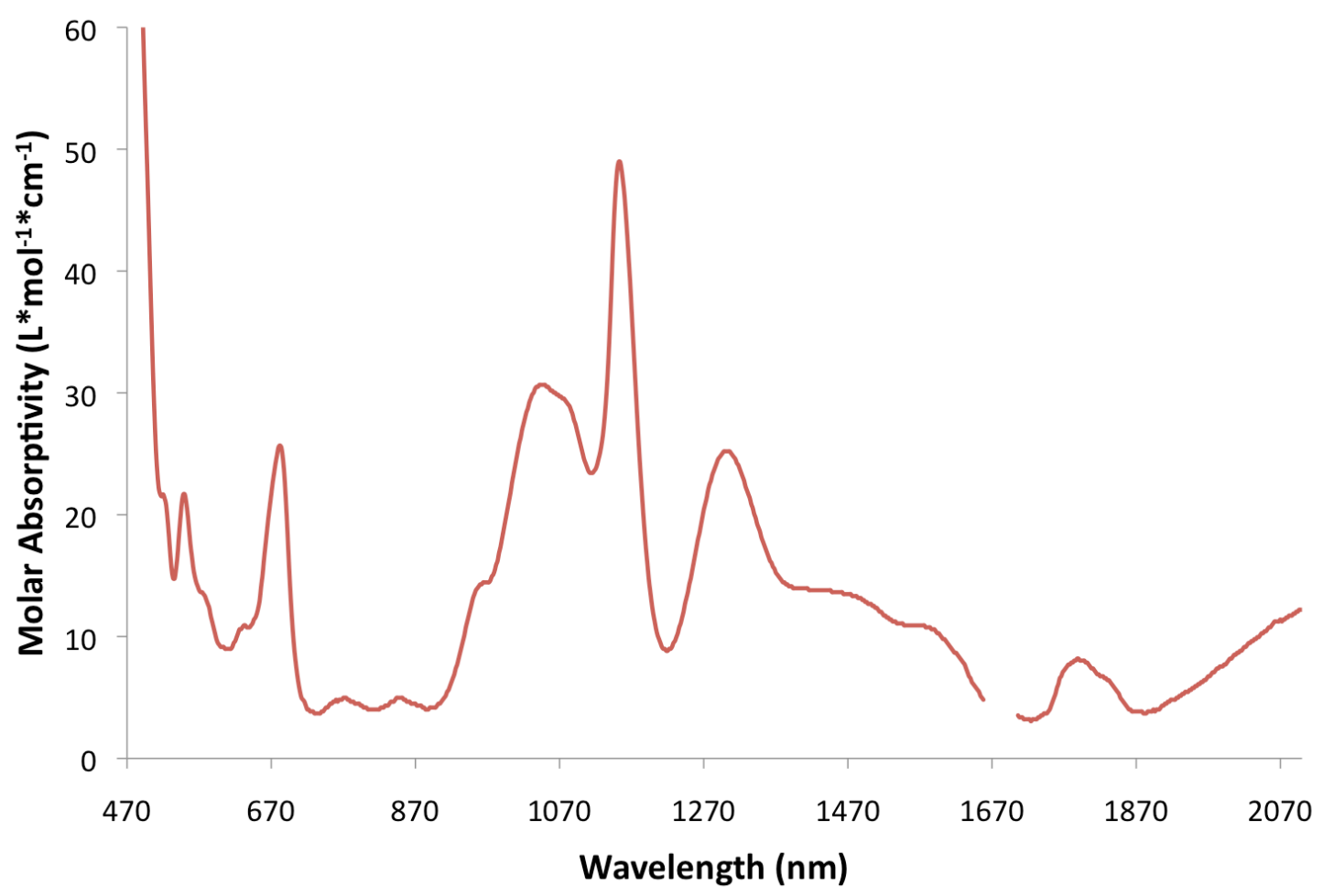

Figure S26. Partial UV-vis/NIR spectrum of complex $3\left(\mathrm{C}_{6} \mathrm{H}_{6}, 6.23 \times 10^{-3} \mathrm{M}\right)$. Solvent absorption has been removed for clarity.

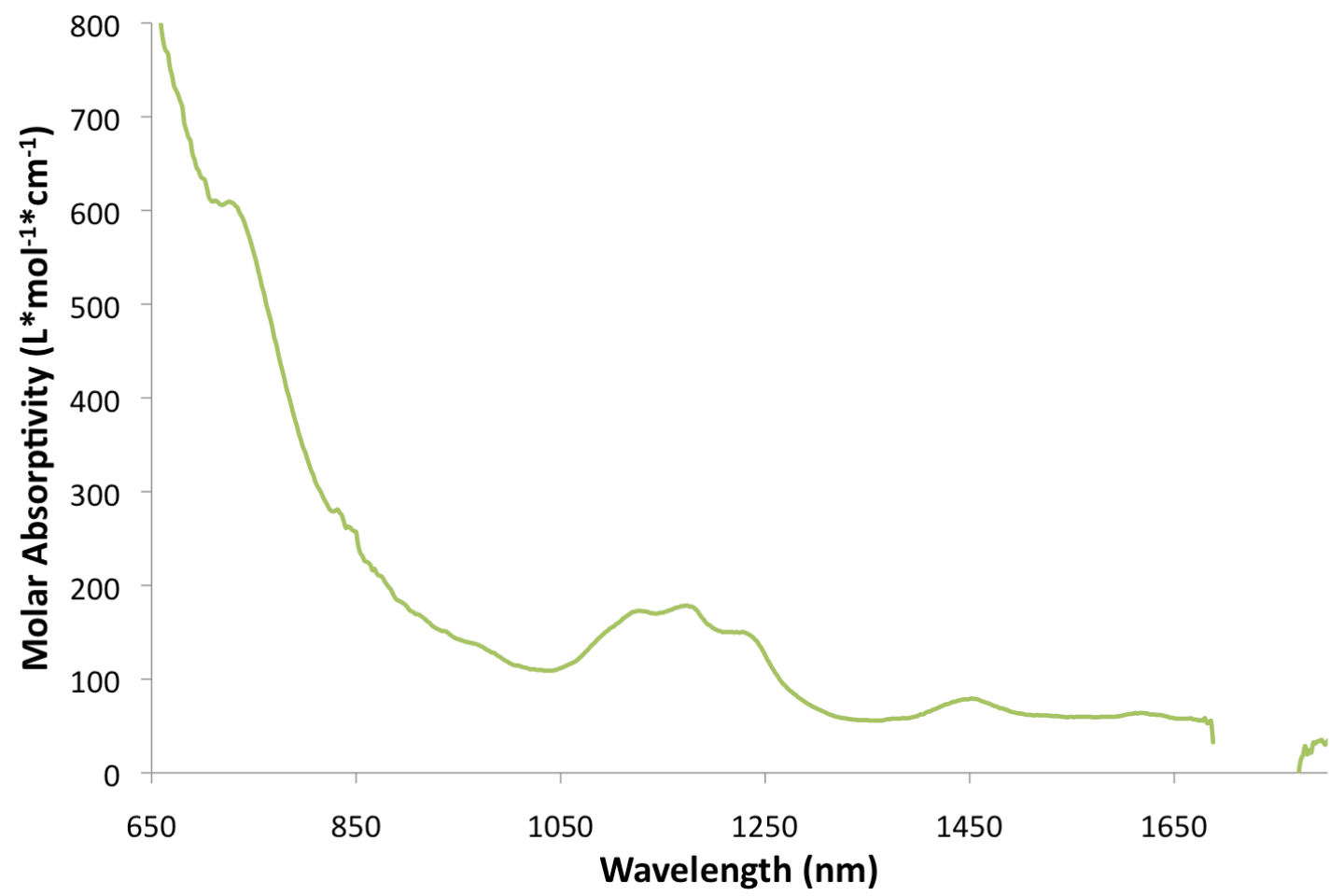

Figure S27. Partial UV-vis/NIR spectrum of complex $4\left(\mathrm{Et}_{2} \mathrm{O}, 1.99 \times 10^{-3} \mathrm{M}\right)$. Solvent absorption has been removed for clarity. 


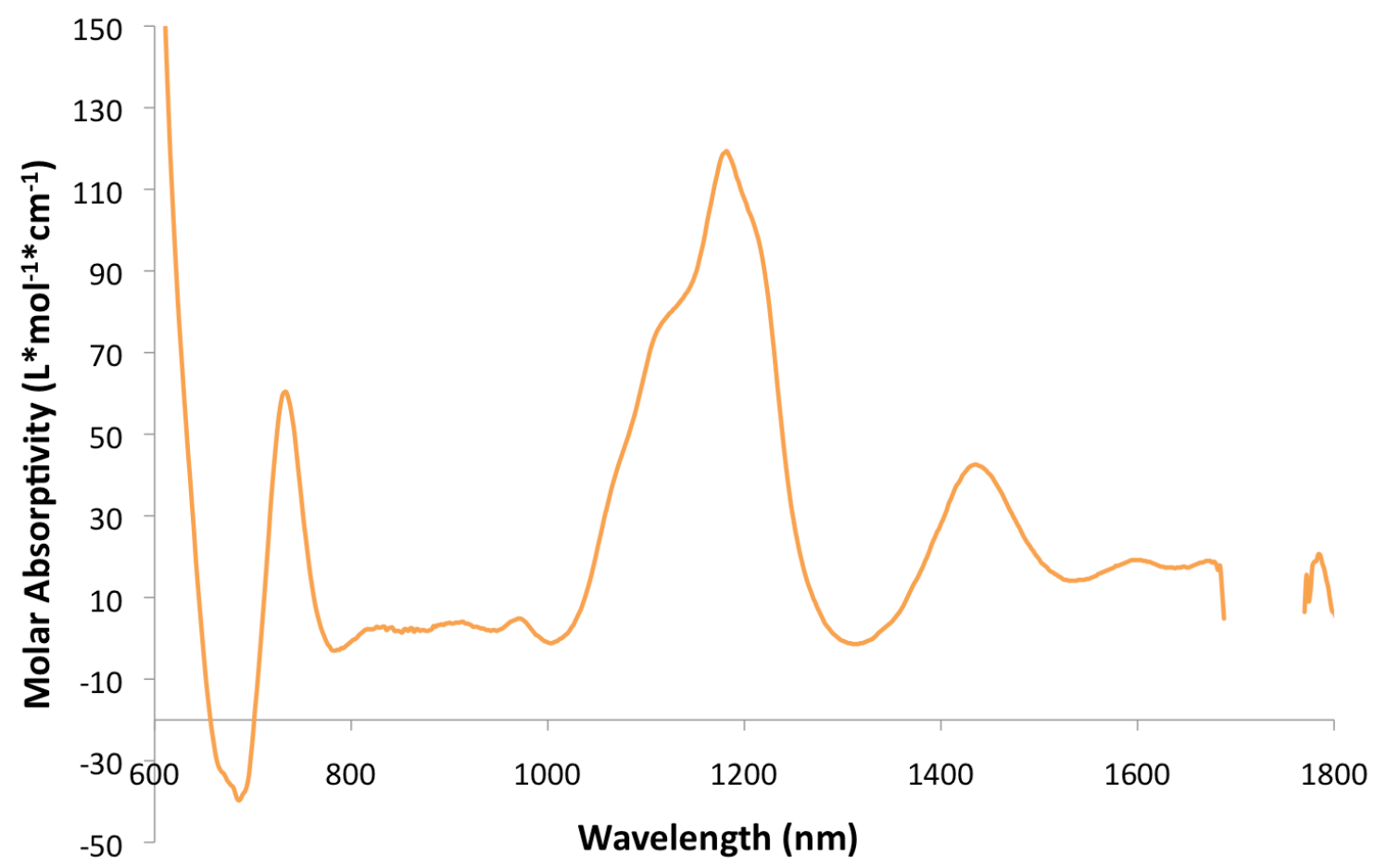

Figure S28. Partial UV-vis/NIR spectrum of complex $5\left(\mathrm{Et}_{2} \mathrm{O}, 4.97 \times 10^{-3} \mathrm{M}\right)$. Solvent absorption has been removed for clarity.

\section{References:}

(1) Wu, J. Y.; Stanzl, B. N.; Ritter, T. J. Am. Chem. Soc. 2010, 132, 13214. 